\title{
Upper-ocean vertical mixing in the Antarctic Polar Front Zone
}

\author{
Boris Cisewski ${ }^{\mathrm{a}, *}$, Volker H. Strass ${ }^{\mathrm{a}}$, Hartmut Prandke \\ a Alfred-Wegener-Institut für Polar- und Meeresforschung, Bremerhaven, Germany \\ ${ }^{\mathrm{b}}$ ISW Wassermesstechnik, Petersdorf, Germany
}

Accepted 15 January 2005

\begin{abstract}
The mixing regime of the upper $180 \mathrm{~m}$ of a mesoscale eddy in the vicinity of the Antarctic Polar Front at $47^{\circ} \mathrm{S}$ and $21^{\circ} \mathrm{E}$ was investigated during the R.V. Polarstern cruise ANT XVIII/2 within the scope of the iron fertilization experiment EisenEx. On the basis of hydrographic CTD and ADCP profiles we deduced the vertical diffusivity $K_{z}$ from two different parameterizations. Since these parameterizations bear the character of empirical functions, based on theoretical and idealized assumptions, they were inter alia compared with Cox-number and Thorpe-scale related diffusivities deduced from microstructure measurements, which supplied the first direct insights into turbulence of this ocean region. Values of $K_{z}$ in the range of $10^{-4}-10^{-3} \mathrm{~m}^{2} \mathrm{~s}^{-1}$ appear as a rather robust estimate of vertical diffusivity within the seasonal pycnocline. Values in the mixed layer above are more variable in time and reach $10^{-1} \mathrm{~m}^{2} \mathrm{~s}^{-1}$ during periods of strong winds. The results confirm a close agreement between the microstructure-based eddy diffusivities and eddy diffusivities calculated after the parameterization of Pacanowski and Philander [1981. Journal of Physical Oceanography 11, 1443-1451].
\end{abstract}

(C) 2005 Elsevier Ltd. All rights reserved.

\section{Introduction}

Vertical or diapycnal mixing in the Antarctic Circumpolar Current (ACC) is being recognized as an important process involved in the overturning circulation of the global ocean (e.g. Rintoul et al., 2001; Wunsch and Ferrari, 2004). The mixing regime of the upper ocean also impacts on the biological processes by regulating the vertical supply of nutrients and by moving phytoplankter along the exponential daylight profile. Despite

\footnotetext{
*Corresponding author.
}

their importance, direct observations of mixing processes and measurements of mixing rates are extremely sparse in the ACC.

Here we report the results of a mixing study conducted in the vicinity of the Antarctic Polar Front (APF) during the iron-fertilization experiment EisenEx (Polarstern Cruise ANT XVIII/2, Smetacek, 2001). The experiment was carried out in Lagrangian manner within a cyclonic eddy of a diameter of nearby $150 \mathrm{~km}$. The eddy, centered at $47^{\circ} \mathrm{S}$ and $21^{\circ} \mathrm{E}$, was obviously shed from the APF by detachment of a northward protruding meander (Fig. 1A). In its interior the eddy carried the 
water mass characteristics and vertical structure that typify the APF, a circumpolar and prominent feature of the ACC. While the mesoscale dynamics associated with eddies and fronts can exert an influence on the vertical stratification and the mixed layer depth (e.g., Strass et al., 2002), the mesoscale horizontal differences in stratification across the eddy (Fig. 1B) were not dramatic, and the Lagrangian manner in which our experiment was conducted allows us to analyze the data with a clear focus on the temporal developments driven by the atmospheric forcing. In this paper, we investigate the mixing regime of the upper $180 \mathrm{~m}$ of the selected eddy over a period of 23 days and present the first direct micro-scale turbulence observations from the mixed layer in the vicinity of the APF.

\section{Instrumentation}

\subsection{CTD profiler}

CTD profiler casts were conducted with a SeaBird 911plus sonde attached to a 24-bottle water sampler. The hydrographic database consisted of 151 CTD casts obtained at 101 hydrographic stations in the Antarctic Circumpolar Current sampled between October 28 and November 29, 2000, from R.V. Polarstern. Study area and station locations are shown in Fig. 1. The instruments were calibrated immediately before and after the cruise. For in situ calibration, temperatures were measured with reversing thermometers, and salinity samples were analyzed with a GuildlineAutosal-8400A salinometer onboard.

The temperature sensor was calibrated at the manufacturer a few months prior to the cruise to an accuracy better than $0.0001{ }^{\circ} \mathrm{C}$. Salinity derived from the CTD measurements was calibrated to a final accuracy of better than 0.002 by comparison to the salinity samples. The standard sampling rate of the CTD was $24 \mathrm{~Hz}$, which corresponded to a sampling period of $0.04 \mathrm{~s}$. Time constants of sensors were in the same order of magnitude: conductivity $0.04 \mathrm{~s}$, temperature $0.06 \mathrm{~s}$, and pressure $0.001 \mathrm{~s}$. The used descent rate was $1.0 \mathrm{~m} \mathrm{~s}^{-1}$; this corresponded to a vertical resolution of $4 \mathrm{~cm}$.
Fine structure estimates were made by calculating $L_{\mathrm{T}}$ using downcast data averaged vertically over $0.4 \mathrm{dbar}$, hence averages including roughly 10 independent raw data values.

\subsection{Acoustic Doppler current profiler}

Current velocities were measured continuously along the ship's track with an RD Instruments, vessel-mounted, $153.6-\mathrm{kHz}$ narrow band ADCP. The transducers were located $11 \mathrm{~m}$ below the water line and were protected against ice floes by an acoustically transparent plastic window. The current measurements were made using a pulse and vertical bin length of $4 \mathrm{~m}$. The averaging interval was $120 \mathrm{~s}$. The reference layer was set to bin $6^{\prime}-15$ avoiding near surface affects and biases near bin 1 . Heading, roll and pitch data from the ship's gyro platforms were used to convert the ADCP velocities into earth coordinates. The ship's velocity was calculated from position fixes obtained by the Global Positioning System (GPS) or DGPS if available. Accuracy of the ADCP velocities mainly depends on the quality of the position fixes and the ship's heading data. Further errors stem from a misalignment of the transducer with the ship's centerline. Since we used ADCP data only collected while the ship was stationary and not steaming through open water, the latter could be neglected. The ADCP data were processed using the CODAS3 software package (developed by E. Firing and colleagues, SOEST, Hawaii).

\subsection{Microstructure profiler}

Since the vertical length scale of motion for typical ocean mixing events is small (of the order of a few $\mathrm{cm}$ ), many efforts were spent during the last two decades to develop instruments and methods for direct micro-scale turbulence measurements (e.g., Lueck et al., 2002). For this study a microstructure profiler type MSS90 was used. The general behaviour of the MSS profiler, produced by Sea \& Sun Technology GmbH in cooperation with ISW Wassermesstechnik Dr. Hartmut Prandke, is described in detail by Prandke et al. (2000). 

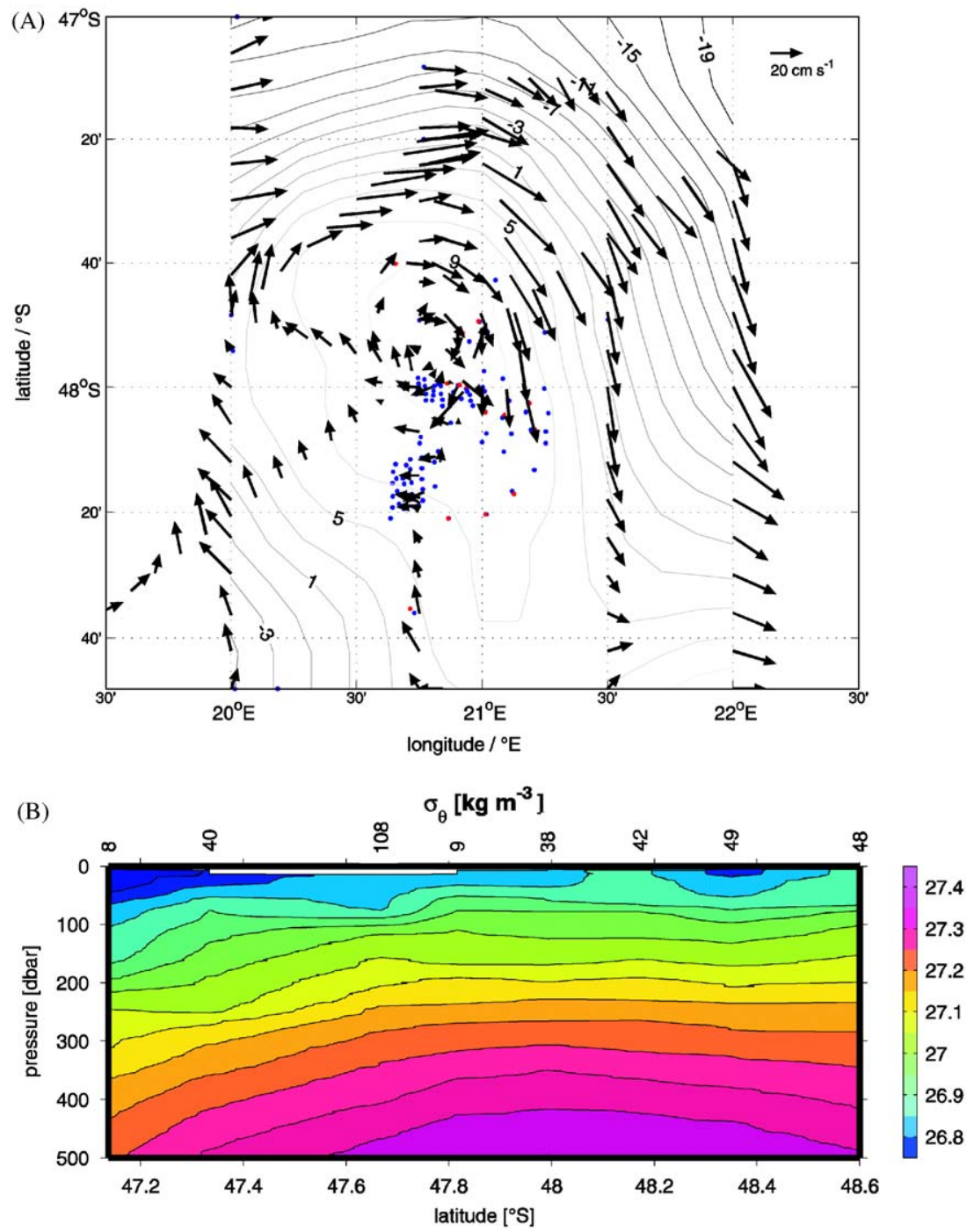

Fig. 1. (A) ADCP velocity vectors averaged between 150 and $200 \mathrm{~m}$ and $10 \mathrm{~km}$ along track and streamfunction $\psi\left[1000 \mathrm{~m}^{2} \mathrm{~s}^{-1}\right.$ ] showing a closed cyclonic circulation centered at $47.85^{\circ} \mathrm{S}, 20.75^{\circ} \mathrm{E}$, which extends over roughly $100-150 \mathrm{~km}$ diameter, location of CTD (blue circles) and MSS stations (red circles); and (B) vertical distribution of $\sigma_{\theta}$ along a N/S cross section at $\sim 20.8^{\circ} \mathrm{E}$.

The MSS profiler is a loosely tethered, freesinking instrument for simultaneous microstructure and precision measurements of physical parameters in marine and limnic waters. It was designed for vertical profiling within the upper $400 \mathrm{~m}$. The data were transmitted via electrical cable to an on board unit and further to a data acquisition PC. The sinking rate of the profiler was adjusted to approx. $0.8 \mathrm{~m} \mathrm{~s}^{-1}$. The MSS profiler was equipped with a microstructure shear sensor
(PNS98), a microstructure temperature sensor (FP07), and standard CTD sensors for precision measurements. All sensors were mounted at the measuring head of the profiler (sensor end). The microstructure sensors were placed at the tip of a slim shaft, about $150 \mathrm{~mm}$ in front of the CTD sensors. The sampling rate for all sensors was 1024 samples per second, the resolution was 16 bit. Altogether, 80 MSS casts were performed at 16 preselected hydrographic stations. However, 
because the condition of undisturbed free fall of the profiler was not perfectly met, the microstructure shear data could not be used for this study. This problem, however, did not affect the MSS measurements of the $\mathrm{T} \& \mathrm{~S}$ finestructure.

\subsection{Meteorological observations}

During the EisenEx cruise many nautical and scientific parameters were collected from a multitude of measuring devices installed on R.V. Polarstern permanently and archived by the ship's Polarstern Data System (PODAS). Extracted time series of the wind speed, air temperature, relative humidity, sea-surface temperature, surface salinity, global radiation, and precipitation were used to investigate the meteorological forcing of the mixed-layer within the study area. The wind-speed data, which were collected by an anemometer attached to the ship mast at a height of $37 \mathrm{~m}$, were recalculated to a reference height of $10 \mathrm{~m}$ to correct for thermal stability effects following Large and Pond (1981).

\section{Methods}

\subsection{Mixed layer depth}

The mixed-layer depth (ML) was assumed to extend from the surface to that depth where vertical changes in the variables of state $(T, S, \sigma)$ were detectable. Here, a difference criterion was used to define the mixed layer depth (MLD) from a density profile. A difference criterion is usually defined as that depth where the property had changed by a certain amount from the surface value. For this study the MLD was defined as that depth at which the calculated in situ density increased by $\Delta \sigma_{\mathrm{T}}=0.02$ compared to the surface value.

\subsection{Meteorological forcing of the mixed layer}

Energy driving the turbulent mixing in the upper ocean is provided by the wind stress and the surface buoyancy flux. To analyze for the wind forcing on the mixed layer, we calculated the energy flux as

$E_{10}=\tau U_{10}$,

where $\tau$ is the wind stress and $U_{10}$ is the wind speed at $10 \mathrm{~m}$. According to Niiler and Kraus (1977) the work done by the wind on the mixed layer is proportional to $u_{*}^{3}$, where $u_{*}$ is the friction velocity, which is the characteristic velocity scale for turbulent shear flows, and determines the velocity scale of turbulence within the mixed layer

$u_{*}^{3}=\left(\frac{\tau}{\rho_{\mathrm{w}}}\right)^{3 / 2}$.

The other source of energy, the surface buoyancy flux, was estimated as

$B=\frac{g}{\rho_{\mathrm{w}}}\left[\frac{\alpha}{c_{\mathrm{w}}} Q+\frac{\beta s}{L(1-s)} \mathrm{LE}\right]$,

where $g$ is the acceleration due to gravity, $\alpha$ the thermal expansion coefficient, $\beta$ the haline contraction coefficient, $c_{\mathrm{w}}$ the specific heat of seawater, $Q$ the net heat flux from the ocean, $s$ the salinity, $L$ is the latent heat of evaporation, and LE represents the latent heat flux. The buoyancy flux contains contributions from the surface heat flux and the surface fresh water flux.

The total heat flux from atmosphere to ocean is given by

$Q=\mathrm{SE}+\mathrm{LE}+F$,

where SE is the sensible heat flux, LE the latent heat flux and $F$ is the net radiative flux at the surface. Negative $Q$ values correspond to a flux from ocean to atmosphere. Each component of the $Q$ was computed after the algorithms provided by Häkkinen and Cavalieri (1989).

\subsection{Estimation of the vertical eddy diffusivity and other turbulent quantities}

To investigate the vertical mixing regime of the upper $180 \mathrm{~m}$ of the study area, we deduce the vertical eddy diffusivity $K_{z}$ from four different methods, which are explained below. 80 MSS casts (Table 1) performed at 16 different stations provide direct measurements of Thorpe displacements and Cox numbers. Furthermore we deduce the vertical diffusivity $K_{z}$ from two different 
parameterizations applied to CTD and ADCP data from 18 stations. In subsequence, this allows for an intercomparison of turbulence parameters derived by different methods involving different degrees of parameterization.

Two vertical length scales relevant to turbulence in stratified flows are in common usage, the Thorpe scale $L_{\mathrm{T}}$ and the Ozmidov scale $L_{\mathrm{O}}$. For estimating the length scales of turbulent overturns in a stratified turbulent layer, we use Thorpe's method (Thorpe, 1977). This method consists of reordering an observed potential density profile or temperature profile, which may contain inversions, into a stable monotonic profile, which contains no inversions. Reordering the profile so as to achieve static stability forms these, so-called vertical Thorpe displacements $d$, which can be interpreted as the result from vertical overturning. The Thorpe scale $L_{\mathrm{T}}$ is given by the root mean square of an ensemble of Thorpe displacements.

$L_{\mathrm{T}}={\overline{\left(d^{2}\right)}}^{1 / 2}$.

It provides a statistical measure of the vertical size of the overturning eddies in that profile segment (Dillon, 1982). We calculate the Thorpe scales both from the density and temperature profiles provided by the MSS profiler and the CTD. Sensor response time corrected temperature

Table 1

MSS data

\begin{tabular}{rlll}
\hline $\begin{array}{l}\text { MSS } \\
\text { station }\end{array}$ & $\begin{array}{l}\text { Number } \\
\text { of casts }\end{array}$ & Date & Position \\
\hline 9 & 6 & 07.11 .2000 & $47.8215^{\circ} \mathrm{S}, 20.8245^{\circ} \mathrm{E}$ \\
11 & 5 & 08.11 .2000 & $47.8553^{\circ} \mathrm{S}, 20.9225^{\circ} \mathrm{E}$ \\
14 & 6 & 10.11 .2000 & $47.9945^{\circ} \mathrm{S}, 20.9112^{\circ} \mathrm{E}$ \\
18 & 5 & 10.11 .2000 & $47.9955^{\circ} \mathrm{S}, 20.91^{\circ} \mathrm{E}$ \\
38 & 5 & 11.11 .2000 & $47.9902^{\circ} \mathrm{S}, 20.8618^{\circ} \mathrm{E}$ \\
41 & 5 & 12.11 .2000 & $47.998^{\circ} \mathrm{S}, 20.9402^{\circ} \mathrm{E}$ \\
43 & 5 & 13.11 .2000 & $48.073^{\circ} \mathrm{S}, 21.0870^{\circ} \mathrm{E}$ \\
45 & 6 & 15.11 .2000 & $48.2848^{\circ} \mathrm{S}, 21.1277^{\circ} \mathrm{E}$ \\
46 & 5 & 16.11 .2000 & $48.3395^{\circ} \mathrm{S}, 21.0145^{\circ} \mathrm{E}$ \\
48 & 5 & 17.11 .2000 & $48.5897^{\circ} \mathrm{S}, 20.713^{\circ} \mathrm{E}$ \\
49 & 5 & 18.11 .2000 & $48.3498^{\circ} \mathrm{S}, 20.8653^{\circ} \mathrm{E}$ \\
78 & 2 & 19.11 .2000 & $47.8238^{\circ} \mathrm{S}, 20.9855^{\circ} \mathrm{E}$ \\
82 & 5 & 23.11 .2000 & $48.0672^{\circ} \mathrm{S}, 21.0135^{\circ} \mathrm{E}$ \\
87 & 5 & 23.11 .2000 & $48.043^{\circ} \mathrm{S}, 21.1887^{\circ} \mathrm{E}$ \\
92 & 5 & 27.11 .2000 & $48.1142^{\circ} \mathrm{S}, 21.2115^{\circ} \mathrm{E}$ \\
108 & 5 & 29.11 .2000 & $47.6692^{\circ} \mathrm{S}, 20.6547^{\circ} \mathrm{E}$ \\
\hline
\end{tabular}

and conductivity measurements were used to compute salinity and density in depth intervals of $0.1 \mathrm{~m}$ for the MSS data.

If the sorting algorithm is applied to the vertical temperature profile, it is important that the water column beforehand is carefully analyzed for the relative influences of salinity and temperature on the density, to make sure that haline contributions are negligible.

From the CTD and MSS profiles estimates of the Brunt-Väisälä frequency squared, $N^{2}$, which gives a measure of the vertical stratification or the static stability of the water column, are obtained according to

$N^{2}=g\left[\beta \frac{\partial S}{\partial z}-\alpha\left(\frac{\partial T}{\partial z}-\Gamma_{z}\right)\right]$,

where $g$ is the acceleration due to gravity, $\alpha$ is the thermal expansion coefficient, $\beta$ is the haline contraction coefficient, $\Gamma_{z}$ is the adiabatic lapse rate, $\partial T / \partial z$ and $\partial S / \partial z$ are the vertical temperature and salinity gradients. $N$ represents the upper limit to the frequency of internal waves.

We deduced the haline and thermal contributions to on the Brunt-Väisälä frequency by separating $N^{2}$ calculated after the HesselbergSverdrup method (Millard et al., 1990):

$N_{\mathrm{T}}^{2}=g \alpha\left(\Gamma_{z}-\frac{\partial T}{\partial z}\right)$

and

$N_{\mathrm{S}}^{2}=g \beta \frac{\partial S}{\partial z}$.

The Ozmidov scale $L_{\mathrm{O}}$, calculated as

$L_{\mathrm{O}}=\sqrt{\frac{\varepsilon}{N^{3}}}$

defines the largest length scale of vertical overturns permitted by the buoyancy force, where $\varepsilon$ is the dissipation rate.

Various measurements during the last two decades have shown that $L_{\mathrm{T}}$ and $L_{\mathrm{O}}$ correlate over a large range in both $N$ and $\varepsilon$ (e.g. Dillon, 1982; Itsweire, 1984; Ferron et al., 1998; Stansfield et al., 2001). The Thorpe scale is nearly equal to the Ozmidov scale (Dillon, 1982; Peters and Gregg, 1988; Moum, 1996; Lorke, 1988). 
Therefore, several authors used this relationship to calculate the dissipation rate $\varepsilon$ from $L_{\mathrm{T}}$ and the cubic Brunt-Väisälä frequency $N^{3}$ (Dillon and Park, 1987; Ferron et al., 1998; Finnigan et al., 2002; Lorke and Wüest, 2002). However, since the measured values of the ratio $L_{\mathrm{O}} / L_{\mathrm{T}}$ vary from 0.65 to 0.95 , the universality of this correlation remains a question (Finnigan et al., 2002). In this context, Baumert and Peters (2000) showed that this ratio is not constant but depends on the gradient Richardson number.

From the squared Thorpe scale, the BruntVäisälä frequency $N$ and the mixing efficiency $\eta$, which is assumed to be 0.2 after Osborn (1980), we calculated the vertical Thorpe scale dependent eddy diffusivity as

$K_{\mathrm{T}}=\eta L_{\mathrm{T}}^{2} N$.

Another direct estimate of the eddy diffusivity from temperature microstructure measurements can be derived from the Osborn-Cox model (Osborn and Cox, 1972)

$K_{\mathrm{C}}=\kappa_{\mathrm{T}} C$,

where $\kappa_{\mathrm{T}}$ is the molecular diffusivity of temperature (approx. $1.4 \times 10^{-7} \mathrm{~m}^{2} \mathrm{~s}^{-1}$ ). The Cox number $C$ is defined as

$C=\frac{\overline{(\mathrm{d} T / \mathrm{d} z)^{2}}}{(\overline{\mathrm{d} T / \mathrm{d} z})^{2}}$

where the over bars denote the average over 1 dbar intervals.

The root-mean-square temperature gradient $\mathrm{d} T / \mathrm{d} z$ is computed from the fast NTC temperature signal. We calculate the local temperature gradient with low pass characteristic as

$\left(\frac{\mathrm{d} T}{\mathrm{~d} z}\right)_{i}=\frac{-T_{i}+4 T_{i-1}-3 T_{i-2}}{p_{i}-p_{i-2}}$.

We can also estimate $K_{\mathrm{C}}$ from the measured thermal dissipation rate $\chi$ and the mean temperature gradient $\partial \bar{T} / \partial z$ following Osborn and Cox (1972),

$K_{\mathrm{C}}=0.5 \bar{\chi}[\partial \bar{T} / \partial z]^{-1}$, where

$\chi=6 \kappa_{\mathrm{T}}\left\langle\left(\frac{\partial T}{\partial z}\right)^{2}\right\rangle$.

Indirect estimates of vertical eddy diffusivities are deduced from two common Richardsonnumber-based parameterizations applied to the CTD and ADCP data. The ADCP velocity components $u$ and $v$, which were averaged over each of the hydrographic station times were used to calculate the squared shear over successive 4-m intervals,

$S^{2}=\left(\frac{\partial u}{\partial z}\right)^{2}+\left(\frac{\partial v}{\partial z}\right)^{2}$

From the squared Brunt-Väisälä frequency, $N^{2}$ (Eq. (6)), and the squared shear, $S^{2}$, the Richardson number $R i$,

$R i=\frac{N^{2}}{S^{2}}$

was calculated. Shear and Brunt-Väisälä frequency were computed at the same vertical resolution of $4 \mathrm{~m}$. According to the manufacturer's specification (RDI, 1987) our $150-\mathrm{kHz}$ narrowband ADCP with a depth cell length of $4 \mathrm{~m}$ and a ping rate of 1 ping per second would have a short-term accuracy of $22 \mathrm{~cm} \mathrm{~s}^{-1}$. The short-term accuracy is defined as the statistical uncertainty in the velocity measurement for 1-s interval. For longer measurements the short-term accuracy increases in proportion to the square root of the measurement interval. Thus, an ensemble length of $120 \mathrm{~s}$ as in our data would result in an error of $\sim 2 \mathrm{~cm} \mathrm{~s}^{-1}$. Since we used only the ADCP data collected while the ship was stationary $(\sim 1 \mathrm{~h})$ and not steaming through open water, errors resulting from the misalignment of the transducer head can be neglected and the short-term accuracy will reduce to $0.5 \mathrm{~cm} \mathrm{~s}^{-1}$. This would result to an error of $1 \times 10^{-6} \mathrm{~s}^{-2}$ for $S^{2}$.

The vertical diffusivity associated with internal waves can be derived using the parameterization given by Gregg (1989),

$K_{\mathrm{G}}=5 \times 10^{-6} \mathrm{~m}^{2} \mathrm{~s}^{-1}\left\langle\frac{S^{4}}{N^{4}}\right\rangle$, 
$S^{4}$ was calculated from the vertical shear between $4-\mathrm{m}$ bins. Furthermore, the coefficient $\left(5 \times 10^{-6}\right)$ assumes that the internal wave variance is consistent with the Garrett-Munk spectrum (Garrett and Munk, 1979; D'Asaro and Morison, 1992).

We also estimate the bulk vertical diffusivity

$$
K_{\mathrm{PP}}=\frac{5 \times 10^{-3} \mathrm{~m}^{2} \mathrm{~s}^{-1}+10^{-4}(1+5 R i)^{2}}{(1+5 R i)^{3}}+10^{-5}
$$

after Pacanowski and Philander (1981). They deduced their parameterization, however, from measurements in the equatorial oceans. Whether it yields realistic values in the Southern Ocean needs to be assessed. We will compare the different estimates of eddy diffusivities; $K_{\mathrm{T}}$ and $K_{\mathrm{C}}$ obtained from microstructure measurements and $K_{\mathrm{G}}$ as well as $K_{\mathrm{PP}}$ derived from parameterizations, against each other and will investigate how their accuracy varies with changes in the physical condition of the upper ocean.

\section{Results and discussion}

\subsection{Mixed layer depth}

Over the duration of the experiment, the winds changed from calm to stormy (Fig. 2A) and the mixed layer depth (Fig. 2B) varied between roughly $20 \mathrm{~m}$ and almost $100 \mathrm{~m}$. The wind record revealed three different strong gales $\left(u>20.8 \mathrm{~m} \mathrm{~s}^{-1}\right)$ occurring on the 12, 21 and the 27 November. During the calmer period before, between the 6 and the 11 November, the MLD was about $26-45 \mathrm{~m}$. Due to the following strong gale, which was characterized by maximum wind speeds of 20-25 $\mathrm{m} \mathrm{s}^{-1}$, the mixed layer deepened to a depth of $80 \mathrm{~m}$. Between the 14 and the 16 November the wind speeds decreased. During this time of relaxation the mixed layer receded to $30 \mathrm{~m}$ depth. The following two days the wind speed increased steadily. Again, the mixed layer deepened; however, increased precipitation ranging from 9.1 to $19.6 \mathrm{~mm} \mathrm{~d}^{-1}$ occurring between the 16 and the 18 November led to a very shallow and light surface layer in the upper $25 \mathrm{~m}$. During the second severe strong gale the 21 November, the station work was temporarily suspended. Two days later the mixed layer was observed extending down to nearly $100 \mathrm{~m}$. Changes in the depth of the Brunt-Väisälä frequency maximum (Fig. 2B) occured roughly in parallel to temporal changes of the MLD, with the Brunt-Väisälä frequency, maximum, however being situated below the MLD, which has been calculated by use of the $\Delta \sigma_{\mathrm{T}}=0.02$ difference criterion. Moreover, the Brunt-Väisälä frequency maximum increased in magnitude, due to entrainment, while the MLD deepened. The long-term trend of the MLD over the 23 days duration of the experiment thus was a deepening, what was surprising given the fact that the experiment was conducted in spring when the mixed layer is expected to shallow due to the seasonal warming.

The different terms in the meteorological forcing of the mixed layer are revealed in Fig. 3. The heat flux, as shown in Fig. 3C, indeed was clearly into the ocean on average. The observed total heat flux at the surface was mainly dominated by the net radiative flux ranged between $2 \mathrm{~W} \mathrm{~m}^{-2}$ at night and $966 \mathrm{~W} \mathrm{~m}^{-2}$ during daytime, whereas the sensible and the latent heat fluxes ranged from -64 to $130 \mathrm{~W} \mathrm{~m}^{-2}$ and from -137 to $97 \mathrm{~W} \mathrm{~m}^{-2}$ (Fig. 3D). The flux of kinetic energy from the wind field into the ocean, $E_{10}$ (Fig. 3A), was comparably low, ranging up to $25 \mathrm{~W} \mathrm{~m}^{-2}$. Related to the wind events but were latent heat losses of up to $137 \mathrm{~W} \mathrm{~m}^{-2}$ (compare figures $3 \mathrm{~A}$ and $\mathrm{D}$ in Fig. 3), which were the major source of energy that drives the mixed layer deepening and hence contributed to explain the observed correlation (Fig. 2) between the wind speed and MLD.

Nevertheless was the mixed layer depth was also significantly correlated with the kinetic wind energy input (Fig. 4), as predicted by the classic model of Pollard et al. (1973) that describes the response of the upper ocean to an imposed wind stress. According to Pollard et al. (1973) MLD is given by

$h \infty u^{*}(t / N)^{1 / 2}$ and $h_{\max }=u^{*} /(N f)^{1 / 2}$,

where $N$ is the Brunt-Väisälä frequency and $f$ the Coriolis parameter. Assuming a steady wind stress 

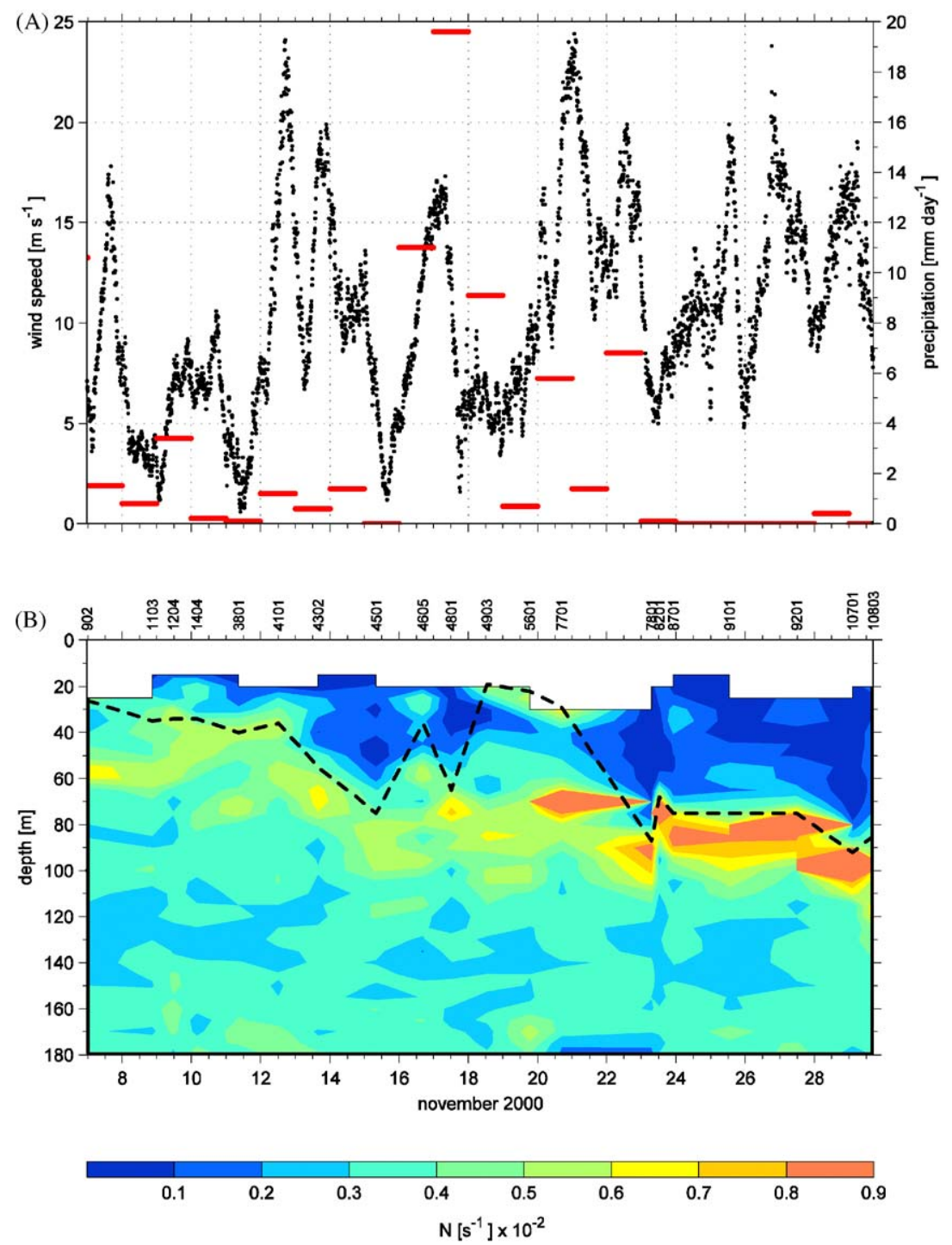

Fig. 2. Time series showing (A) wind speed (black) and precipitation (red), and (B) the vertical distribution of the Brunt-Väisälä frequency (colour scale) and mixed layer depths derived from the difference criterion (dashed line).

blowing over an initially motionless ocean the resultant MLD is predicted as occurring after a time $t$, corresponding to 0.5 inertial periods. Our data, however, indicated that the response is longer, rather three inertial periods long. For the correlation analysis we calculated the energy input from the wind stress by integrating the flux $E_{10}$ over varying time scales, which have been gradually increased to 5 inertial periods, in steps of 0.5 inertial periods. The resultant coefficient of correlation between the integrated energy flux and the mixed layer depth, $r$, amounted to 0.4 , which was not statistically significant, if the integration time was 0.5 inertial periods. However, $r$ increased with extended integration time and converges at 0.83 after three inertial periods 

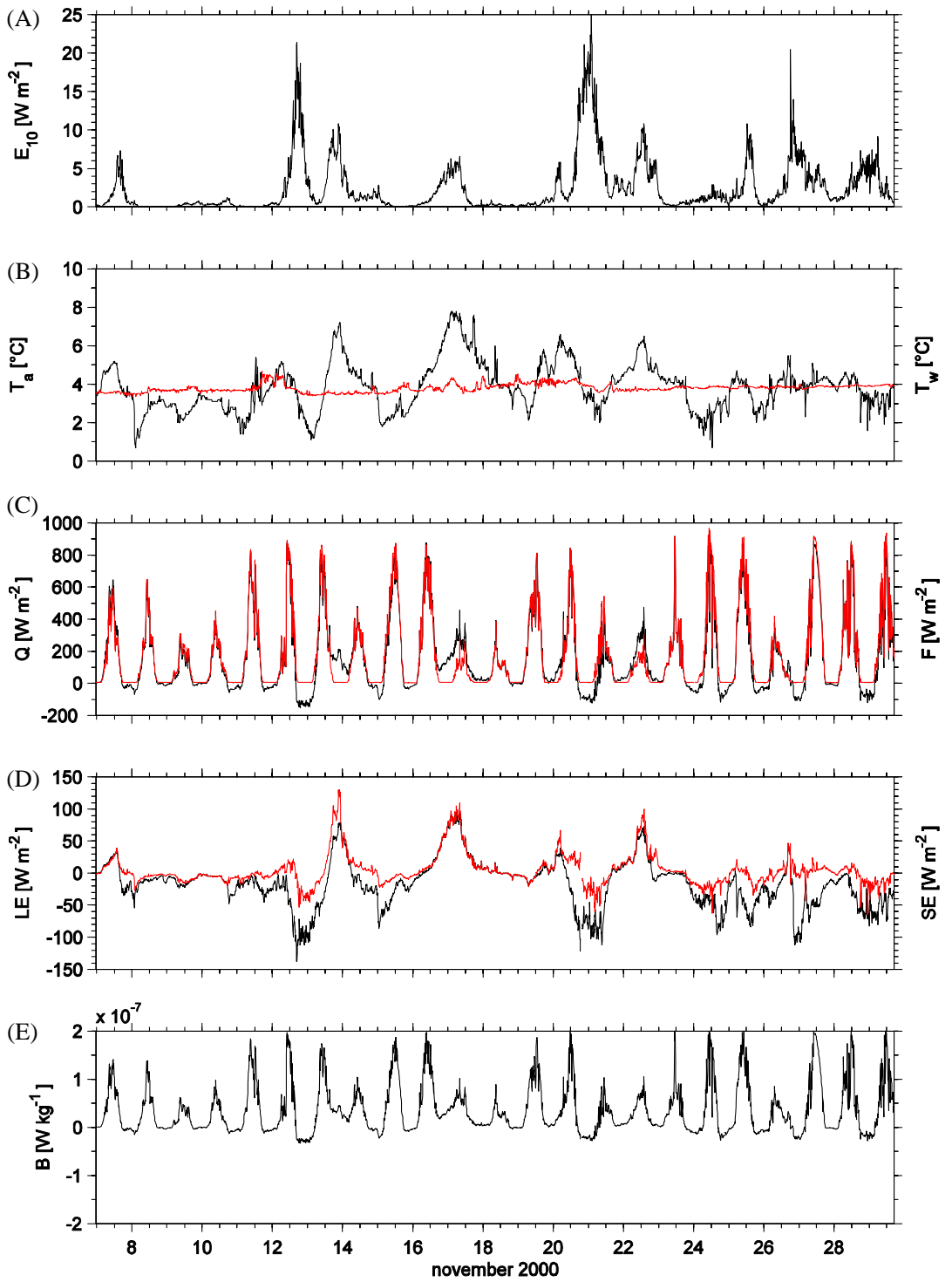

Fig. 3. Ten-minute averages of the meteorological data: (A) $E_{10}$ is the energy flux resulting from the wind stress, (B) air temperature $T_{\mathrm{a}}$ (black) and water temperature $T_{\mathrm{w}}$ (red), (C) total heat flux from atmosphere to ocean $Q$ (black) and net radiative flux $F$ (red), (D) latent heat and sensible fluxes LE (black) and SE (red) and (E) buoyancy flux $B$.

(Figs. 4A and B). At the latitude of our investigations $\left(48^{\circ} \mathrm{S}\right)$, a time period of three inertial periods compare to $48 \mathrm{~h}$. That our data suggest a response time is longer than in the model of Pollard et al. (1973) is likely explained by the fact that our experiment was conducted under highly variable winds, whereas the model assumes a steady wind stress.

\subsection{Measurements and parameterizations of vertical eddy coefficients}

\subsubsection{Estimation of Thorpe scale-based eddy diffusivities}

Many of the observed vertical temperature and density profiles contained regions of static instability. To quantify these finestructures we 

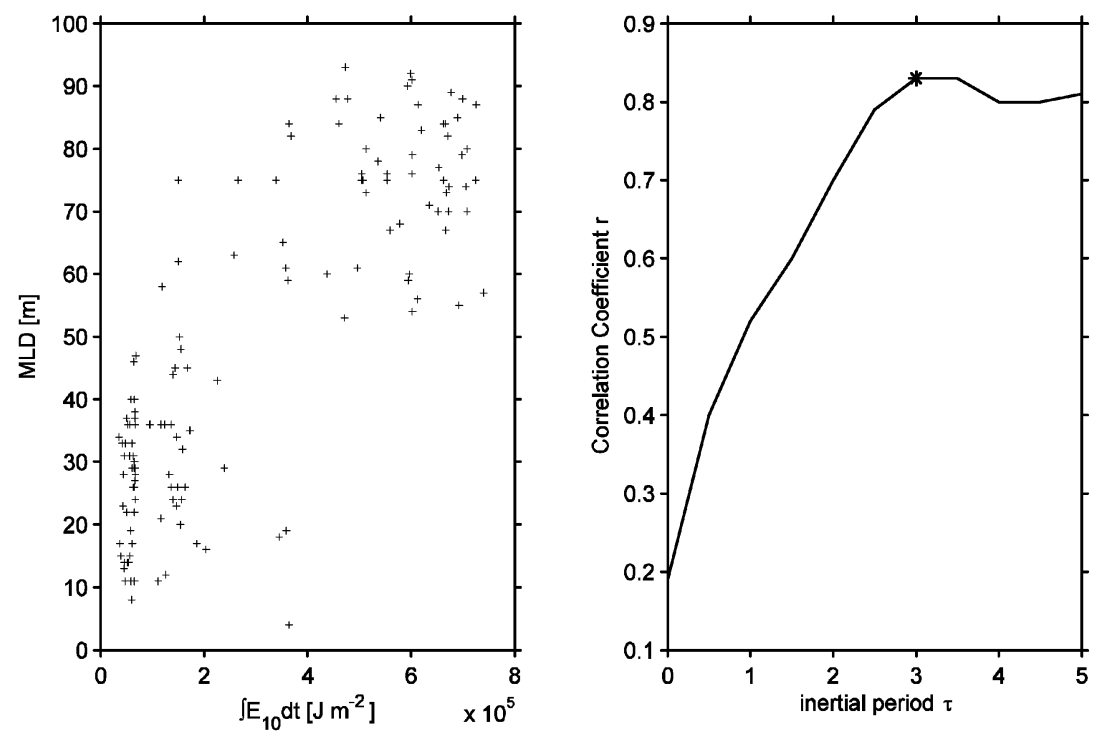

Fig. 4. (A) The mixed layer depth MLD plotted versus the wind-induced energy input, which was calculated by integrating the energy flux $E_{10}$ over three inertial periods, correlation coefficient $r=0.83$ and (B) shows the correlation coefficients, that result for integration times scales varying between 0 and 5 inertial periods.

calculated the Thorpe scale, $L_{\mathrm{T}}$, as described in Section 3.3. We applied Thorpe's method to the vertical temperature and potential density profiles derived from the CTD measurements and the fast NTC temperature signal from the MSS measurements. To give an example for the application of Thorpe's method, we show the results for the CTD station 87 and for a consecutive MSS cast conducted one h later. Both vertical temperature profiles (Figs. 5D and G) look very similar and reveal a staircase structure with two distinct homogeneous layers in the uppermost $25 \mathrm{~m}$ and between around 30 and $80 \mathrm{~m}$.

The black curve in Fig. 5A shows the initial vertical potential density profile (averaged over $0.4 \mathrm{dbar}$ ), whereas the red curve illustrates the monotonically reordered potential density profile. Fig. 5B reveals the calculated Thorpe displacements (black curve) and the resultant Thorpe scales, which were averaged for 4-m bins (red curve). The Thorpe displacements reveal one distinct overturn with vertical dimensions of up to $25 \mathrm{~m}$, centered (zero-crossing) at $18 \mathrm{~m}$. Another layer of, however, smaller overturns, $5 \mathrm{~m}$, can be seen between 50 and $60 \mathrm{~m}$.
Below, signs of instabilities are vanishing. In accordance $N^{2}$, which is illustrated in Fig. 5C as the sum of $N_{\mathrm{T}}^{2}+N_{\mathrm{S}}^{2}$, had its maximum below $80 \mathrm{~m}$ at the base of the mixed layer; the mixed layer depth calculated from applying our difference criterion of $\Delta \sigma_{\mathrm{T}}=0.02$ at this station was $83 \mathrm{~m}$. The resultant profile of $K_{\mathrm{T}}$ (Fig. 5F) shows values ranged between $10^{-4}$ and $10^{-1} \mathrm{~m}^{2} \mathrm{~s}^{-1}$ in the mixed-layer, with a sharp decrease of more than two orders of magnitude at about $30 \mathrm{~m}$, at a depth where the density profile reveals an only tiny step. The sharp decrease of a $K_{\mathrm{T}}$ at $30 \mathrm{~m}$ provides clear evidence of the difference between the actively mixing layer and the mixed layer.

For deriving fine structure estimates from the MSS we used 0.1-dbar averages. Fig. 5H reveals the calculated Thorpe displacements (black curve) and the resultant Thorpe scales, which were averaged for 4-m bins (red curve). The Thorpe displacements show one distinct overturn with vertical dimensions of up to $15 \mathrm{~m}$, centered (zerocrossing) at $17 \mathrm{~m}$. Another layer of three however smaller overturns, $<5 \mathrm{~m}$, can be seen between 30 and $50 \mathrm{~m}$. 
(A)

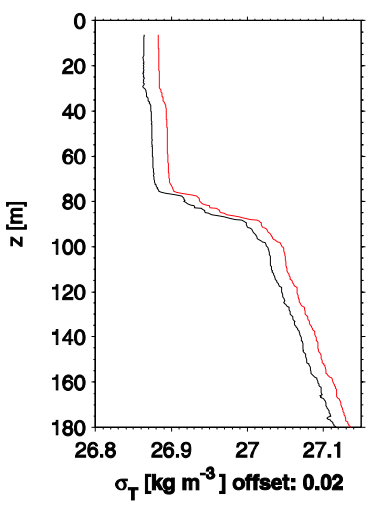

(D)

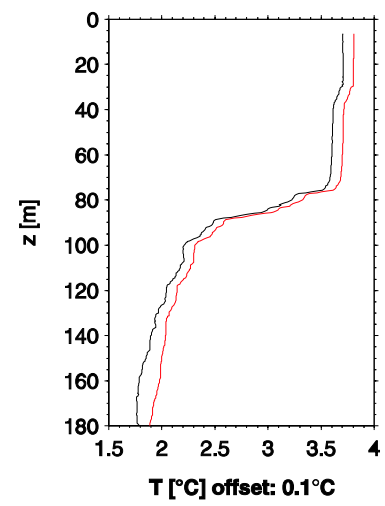

(G)

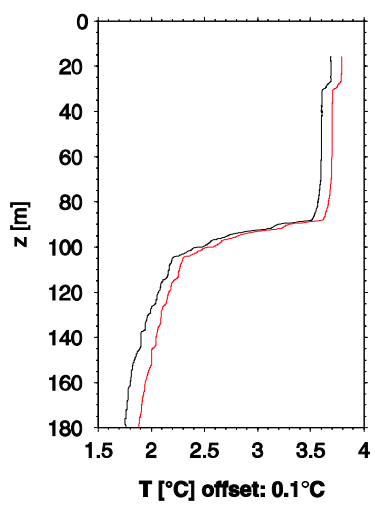

(B)

$\mathrm{L}_{T}$ [m]

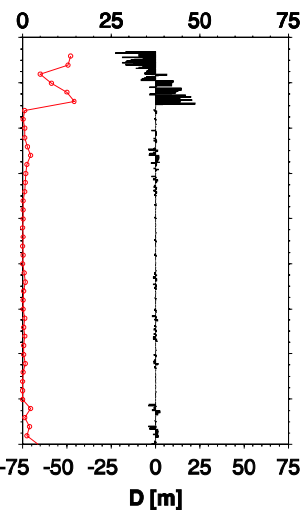

(E)

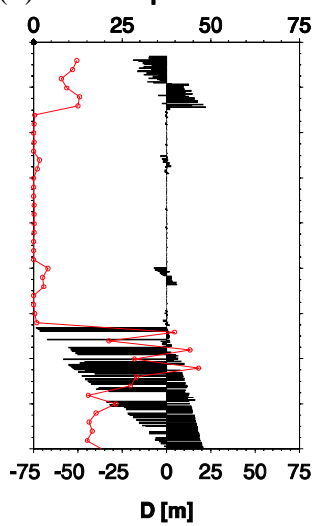

(H)

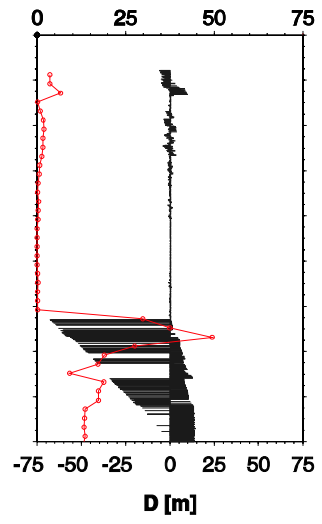

(C)

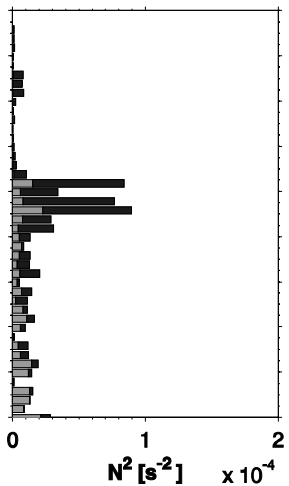

(F)

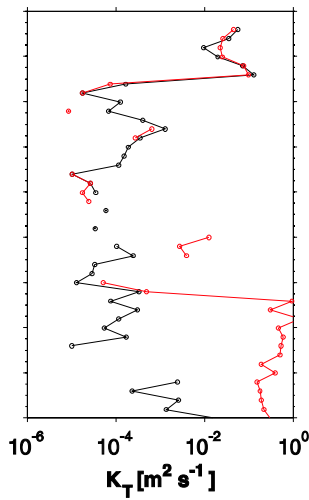

(I)

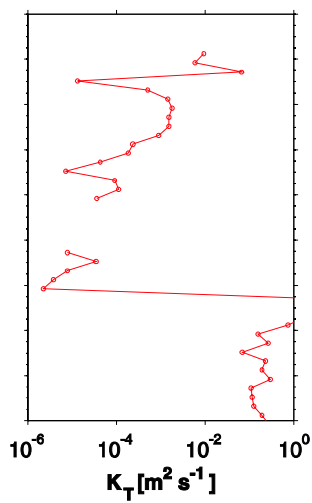

Fig. 5. CTD profiles at station 87 showing: (A) the vertical potential density profile before (black) and after Thorpe reordering (red); the profiles are offset by 0.02 ; (B) Thorpe displacements (black) and derived Thorpe scales (red); (C) thermal and haline contributions (black and grey bars) to the Brunt-Väisälä frequency squared; (D) vertical temperature profile (black) and reordered temperature profile (red); the profiles are offset by $0.1{ }^{\circ} \mathrm{C}$; (E) Thorpe displacements (black) and derived Thorpe scales (red); (F) Thorpe scaledependent vertical eddy diffusivity derived from CTD density (black) and CTD temperature (red); MSS profiles at station 87 showing; (G) vertical temperature profile (black) and reordered temperature profile (red); the profiles are offset by $0.1^{\circ} \mathrm{C}$; $(\mathrm{H}) \mathrm{Thorpe}$ displacements (black) and derived Thorpe scales (red); and (I) Thorpe scale-dependent vertical eddy diffusivity derived fast NTC temperature (red). 
Fig. 5 indicates that data obtained with a CTD sonde were sufficient to resolve the major instabilities, however note that $L_{\mathrm{T}}=0$ does not necessarily imply that there is no overturn, but that we do not have a sufficient resolution to infer the existence of a smallish overturn (Ferron et al., 1998). Following Galbraith and Kelley (1996), the vertical resolution of $0.4 \mathrm{dbar}$ (CTD) and $0.1 \mathrm{dbar}$ (MSS) does not allow for detection of overturns that are thinner than 2 and $0.5 \mathrm{~m}$. Comparison of the vertical profiles of eddy diffusivity $K_{\mathrm{T}}$, calculated from the temperature derived Thorpe displacements estimated from both CTD and MSS, shows that both are very similar by vertical shape as well as by magnitude. The similarity of these two profiles, despite their difference in resolution, is explained by the fact that $K_{\mathrm{T}}$ depends on Thorpe scale squared (Eq. (10)), i.e. that smallish overturns have relatively little influence. Please note that part of the deviations between the CTD- and MSSbased profiles of $K_{\mathrm{T}}$ relate to the fact that these two measurements were not taken at exactly the same time.

To analyze the water column with respect to the relative influence of salinity and temperature on density, we separated $N^{2}$ as outlined in Eqs. (8) and (9). The results are shown in the Fig. 5C. Both the calculated Thorpe scales and the Thorpe scalebased vertical eddy diffusivities (Fig. 5F) agreed well in the upper $80 \mathrm{~m}$ of the water column, showing that the observed density instabilities in this upper depth range were dominated by temperature anomalies. In contrast, within the deeper layer below $80 \mathrm{~m}$, but especially in the depth range below $120 \mathrm{~m}$ the density- and temperature-based Thorpe scales differ. This difference is caused by an increase with depth of the importance of the haline contributions to the Brunt-Väisälä frequency, and to the vertical density structure, relative to the thermal contributions.

This analysis was made for all selected stations and shows that all chosen methods, which deduce the eddy coefficient from temperature variations alone, are only applicable for the upper $80-120 \mathrm{~m}$. For our statistical analysis, temperature-based eddy diffusivities are therefore only taken into account within those upper depth ranges where temperature dominates the density structure.

\subsubsection{Estimation of vertical eddy diffusivities after Osborn and Cox (1972)}

Under the assumption that the generation of temperature fluctuations by vertical turbulence in a mean temperature gradient is balanced by the molecular dissipation of these fluctuations, we estimated the vertical eddy diffusivity of heat after Osborn and Cox (1972). We applied the OsbornCox method to the microstructure measurements derived from the NTC sensor. To give an example, we show the results for one single MSS profile conducted at station 87 . The vertical temperature and salinity profiles (Fig. 6A) reflect the staircase structure of the density field and show two distinct gradients, one weak at around $30 \mathrm{~m}$ and the other strong between 80 and $100 \mathrm{~m}$. A quasihomogenous layer characterizes the profile between 30 and $80 \mathrm{~m}$. By analyzing thermal and haline contributions to the Brunt-Väisälä-Frequency squared (Fig. 6D) we show that haline effects corrupt the $K_{\mathrm{C}}$ values in the pycnocline below $90 \mathrm{~m}$.

The Cox number, which is defined as the ratio of the mean over the squared temperature gradients divided by the square of the mean temperature gradient, reveals a strong decrease by six orders of magnitude within the mixed layer and remains at values ranging between $10^{3}$ and $10^{6}$ (Fig. 6E) below. The derived eddy diffusivity of heat (Fig. $6 \mathrm{~F}$ ) ranges between $10^{-4}$ and $10^{1} \mathrm{~m}^{2} \mathrm{~s}^{-1}$ within the mixed layer and remains at around $10^{-2} \mathrm{~m}^{2} \mathrm{~s}^{-1}$ below, which is up to five orders of magnitude higher than the values of $K$ obtained by all the other methods (see Table 2, explained later). It is possible that the very high mixed-layer values of $K_{\mathrm{C}}$ result from errors associated with the small temperature gradients in that quasi-homogeneous regime. To exclude this possible error as well as the effect of haline gradients in the deeper part of the thermocline, we will for the further discussion consider only $K_{\mathrm{C}}$ determined in the depth range of the upper thermocline where temperature dominates the density structure and strong vertical gradients are evident. 

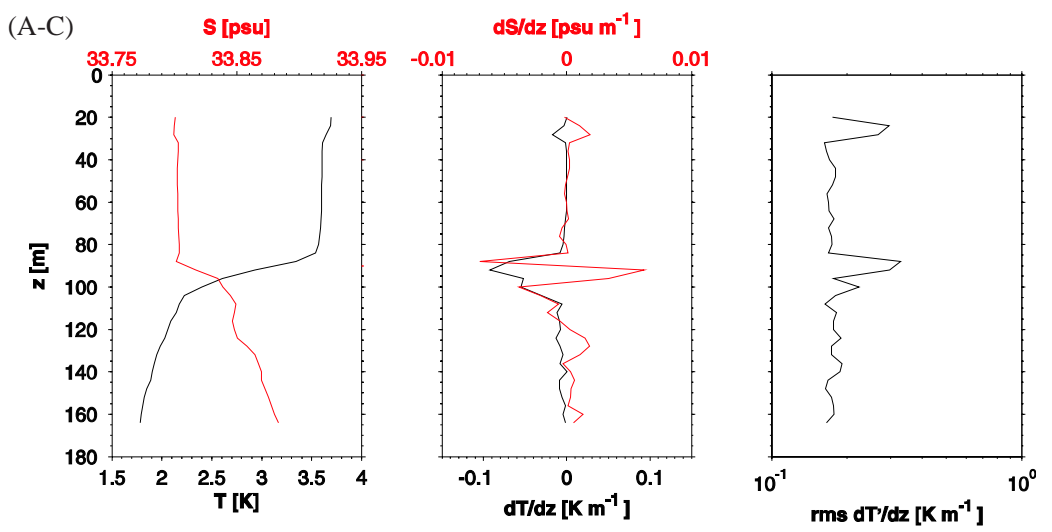

(D-F)
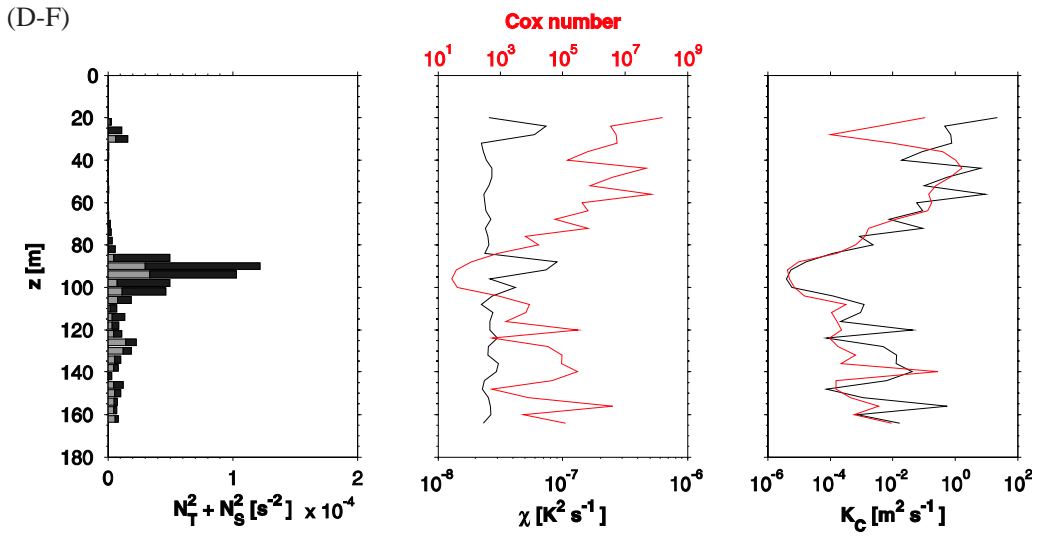

Fig. 6. MSS profile 2 at station 87 showing: (A) the vertical temperature profile (black) and the vertical salinity profile (red); (B) mean vertical temperature gradient (black) and salinity gradient (red); (C) vertical root mean square temperature gradient; (D) thermal and haline contributions (black and grey bars) to the Brunt-Väisälä frequency squared; (E) vertical profile of dissipation rate of heat $\chi$ (black) and Cox number (red); and (F) vertical eddy diffusivity of heat derived from Eq. (11) (black) and Eq. (14) (red).

\subsubsection{Estimation of parameterized eddy diffusivities}

The Richardson-number-dependent parameterizations of Pacanowski and Philander (1981) and of Gregg (1989), which are outlined in Section 3, were applied to the CTD and the ADCP data. To give an example, we use again CTD station 87. From the averaged ADCP velocities (Fig. 7A) we derived the current shear squared. As mentioned in Section 3.3, an estimate of noise in the ADCP calculation of shear is required in order to assess the accuracy of the resulting Richardson-numberdependent parameterizations. We have shown that the short-term accuracy will reduce to $0.5 \mathrm{~cm} \mathrm{~s}^{-1}$ after averaging over a duration of $60 \mathrm{~min}$. This would result to an error of $1 \times 10^{-6} \mathrm{~s}^{-2}$ in squared shear, $S^{2}$. This value roughly corresponds to the minima of squared shear occurring in the profiles shown in the Fig. 7. The major variations of $S^{2}$, which dominate the vertical distribution of the derived estimates of vertical eddy diffusivity, are thus by 1-2 orders of magnitude higher than the error level.

The squared shear also dominates the vertical distributions $K_{\mathrm{G}}$ as well as $K_{\mathrm{PP}}$ and makes them appear correlated. Quantitatively, however, $K_{\mathrm{G}}$ tends to be 1-2 or even more orders of magnitude smaller than $K_{\mathrm{PP}}$ in the depth range below the mixed layer.

To examine the influence of vertical resolution on the derived parameterized eddy diffusivities, the shear and Brunt-Väisälä frequency are also 
Table 2

Vertically averaged eddy coefficients, calculated for the mixed layer and the upper thermocline of each station

\begin{tabular}{|c|c|c|c|c|}
\hline St. & $K_{\mathrm{PP}}\left(\mathrm{m}^{2} \mathrm{~s}^{-1}\right)$ & $K_{\mathrm{G}}\left(\mathrm{m}^{2} \mathrm{~s}^{-1}\right)$ & $K_{\mathrm{C}}\left(\mathrm{m}^{2} \mathrm{~s}^{-1}\right)$ & $K_{\mathrm{T}}^{\mathrm{MSS}}\left(\mathrm{m}^{2} \mathrm{~s}^{-1}\right)$ \\
\hline 9 & $9.45 \times 10^{-4}\left( \pm 7.93 \times 10^{-4}\right)$ & & & $1.79 \times 10^{-3}\left( \pm 2.08 \times 10^{-3}\right)$ \\
\hline 9 & $2.43 \times 10^{-4}\left( \pm 9.68 \times 10^{-5}\right)$ & $5.04 \times 10^{-5}\left( \pm 2.80 \times 10^{-5}\right)$ & $3.17 \times 10^{-4}\left( \pm 2.29 \times 10^{-4}\right)$ & $1.15 \times 10^{-4}\left( \pm 1.01 \times 10^{-4}\right)$ \\
\hline 11 & $5.81 \times 10^{-4}\left( \pm 9.16 \times 10^{-4}\right)$ & & & $8.89 \times 10^{-4}\left( \pm 1.3 \times 10^{-3}\right)$ \\
\hline 11 & $1.22 \times 10^{-4}\left( \pm 5.84 \times 10^{-5}\right)$ & $1.71 \times 10^{-5}\left( \pm 1.02 \times 10^{-5}\right)$ & $2.45 \times 10^{-5}\left( \pm 1.14 \times 10^{-5}\right)$ & $8.7 \times 10^{-6}\left( \pm 1.24 \times 10^{-5}\right)$ \\
\hline 14 & $6.93 \times 10^{-4}\left( \pm 7.24 \times 10^{-4}\right)$ & & & $4.77 \times 10^{-4}\left( \pm 7.11 \times 10^{-4}\right)$ \\
\hline 14 & $1.14 \times 10^{-4}\left( \pm 1.09 \times 10^{-4}\right)$ & $2.22 \times 10^{-5}\left( \pm 2.88 \times 10^{-5}\right)$ & $4.0 \times 10^{-5}\left( \pm 3.21 \times 10^{-5}\right)$ & $2.47 \times 10^{-5}\left( \pm 2.10 \times 10^{-5}\right)$ \\
\hline 18 & $5.64 \times 10^{-4}\left( \pm 3.37 \times 10^{-4}\right)$ & & & $1.94 \times 10^{-3}\left( \pm 2.42 \times 10^{-3}\right)$ \\
\hline 18 & $3.55 \times 10^{-4}\left( \pm 4.61 \times 10^{-4}\right)$ & $1.5 \times 10^{-3}\left( \pm 2.3 \times 10^{-3}\right)$ & $3.3 \times 10^{-3}\left( \pm 7.9 \times 10^{-3}\right)$ & $2.19 \times 10^{-4}\left( \pm 4.03 \times 10^{-4}\right)$ \\
\hline 38 & $3.49 \times 10^{-3}\left( \pm 4.18 \times 10^{-3}\right)$ & & & $8.21 \times 10^{-3}\left( \pm 5.43 \times 10^{-3}\right)$ \\
\hline 38 & $2.97 \times 10^{-4}\left( \pm 2.88 \times 10^{-4}\right)$ & $1.39 \times 10^{-4}\left( \pm 1.84 \times 10^{-4}\right)$ & $4.35 \times 10^{-5}\left( \pm 4.64 \times 10^{-5}\right)$ & $5.84 \times 10^{-5}\left( \pm 7.51 \times 10^{-5}\right)$ \\
\hline \multicolumn{5}{|c|}{ Mean values for stage 1} \\
\hline & $7.08 \times 10^{-4}\left( \pm 6.49 \times 10^{-4}\right)$ & & & $2.31 \times 10^{-3}\left( \pm 3.47 \times 10^{-3}\right)$ \\
\hline & $2.26 \times 10^{-4}\left( \pm 2.54 \times 10^{-4}\right)$ & $3.42 \times 10^{-4}\left( \pm 1.1 \times 10^{-3}\right)$ & $7.46 \times 10^{-4}\left( \pm 3.54 \times 10^{-3}\right)$ & $8.51 \times 10^{-5}\left( \pm 1.92 \times 10^{-4}\right)$ \\
\hline 41 & $2.0 \times 10^{-3}\left( \pm 1.24 \times 10^{-3}\right)$ & & & $2.42 \times 10^{-2}\left( \pm 7.25 \times 10^{-3}\right)$ \\
\hline 41 & $2.81 \times 10^{-4}\left( \pm 2.06 \times 10^{-4}\right)$ & $3.22 \times 10^{-4}\left( \pm 3.52 \times 10^{-4}\right)$ & $8.4 \times 10^{-3}\left( \pm 1.83 \times 10^{-2}\right)$ & $4.2 \times 10^{-3}\left( \pm 6.1 \times 10^{-3}\right)$ \\
\hline 43 & $1.1 \times 10^{-3}\left( \pm 8.07 \times 10^{-4}\right)$ & & & $8.72 \times 10^{-3}\left( \pm 7.82 \times 10^{-3}\right)$ \\
\hline 43 & $1.33 \times 10^{-4}\left( \pm 1.25 \times 10^{-4}\right)$ & $4.95 \times 10^{-5}\left( \pm 6.81 \times 10^{-5}\right)$ & $8.7 \times 10^{-3}\left( \pm 1.5 \times 10^{-2}\right)$ & $2.4 \times 10^{-3}\left( \pm 1.9 \times 10^{-3}\right)$ \\
\hline 45 & $1.37 \times 10^{-3}\left( \pm 8.29 \times 10^{-4}\right)$ & & & $1.4 \times 10^{-3}\left( \pm 1.21 \times 10^{-3}\right)$ \\
\hline 45 & $7.28 \times 10^{-4}\left( \pm 2.63 \times 10^{-5}\right)$ & $9.33 \times 10^{-6}\left( \pm 4.71 \times 10^{-6}\right)$ & $3.26 \times 10^{-5}\left( \pm 3.43 \times 10^{-5}\right)$ & $1.25 \times 10^{-4}\left( \pm 2.5 \times 10^{-4}\right)$ \\
\hline 46 & $9.96 \times 10^{-4}\left( \pm 7.43 \times 10^{-4}\right)$ & & & $4.87 \times 10^{-3}\left( \pm 3.56 \times 10^{-3}\right)$ \\
\hline 46 & $1.13 \times 10^{-4}\left( \pm 9.84 \times 10^{-5}\right)$ & $2.27 \times 10^{-5}\left( \pm 2.56 \times 10^{-5}\right)$ & $3.32 \times 10^{-4}\left( \pm 2.93 \times 10^{-4}\right)$ & $1.4 \times 10^{-3}\left( \pm 1.1 \times 10^{-3}\right)$ \\
\hline 48 & $1.38 \times 10^{-3}\left( \pm 1.46 \times 10^{-3}\right)$ & & & $2.01 \times 10^{-2}\left( \pm 1.8 \times 10^{-2}\right)$ \\
\hline 48 & $1.43 \times 10^{-4}\left( \pm 1.46 \times 10^{-4}\right)$ & $3.51 \times 10^{-5}\left( \pm 4.59 \times 10^{-5}\right)$ & $1.2 \times 10^{-3}\left( \pm 1.7 \times 10^{-3}\right)$ & $1.25 \times 10^{-3}\left( \pm 1.3 \times 10^{-3}\right)$ \\
\hline 49 & $4.8 \times 10^{-4}\left( \pm 3.75 \times 10^{-4}\right)$ & & & $8.86 \times 10^{-4}\left( \pm 1.82 \times 10^{-2}\right)$ \\
\hline 49 & $1.72 \times 10^{-4}\left( \pm 1.33 \times 10^{-4}\right)$ & $3.06 \times 10^{-5}\left( \pm 2.95 \times 10^{-5}\right)$ & $1.21 \times 10^{-4}\left( \pm 1.44 \times 10^{-4}\right)$ & $1.18 \times 10^{-3}\left( \pm 1.3 \times 10^{-3}\right)$ \\
\hline \multicolumn{5}{|c|}{ Mean values for stage 2} \\
\hline & $1.16 \times 10^{-3}\left( \pm 9.07 \times 10^{-4}\right)$ & & & $9.51 \times 10^{-3}\left( \pm 1.27 \times 10^{-2}\right)$ \\
\hline & $1.52 \times 10^{-4}\left( \pm 1.4 \times 10^{-4}\right)$ & $7.82 \times 10^{-5}\left( \pm 1.77 \times 10^{-4}\right)$ & $3.12 \times 10^{-3}\left( \pm 8.11 \times 10^{-3}\right)$ & $1.75 \times 10^{-3}\left( \pm 2.85 \times 10^{-3}\right)$ \\
\hline 78 & $2.09 \times 10^{-1}\left( \pm 5.65 \times 10^{-1}\right)$ & & & $8.01 \times 10^{-2}\left( \pm 4.31 \times 10^{-2}\right)$ \\
\hline 78 & $1.37 \times 10^{-4}\left( \pm 1.83 \times 10^{-4}\right)$ & $8.74 \times 10^{-7}\left( \pm 8.65 \times 10^{-7}\right)$ & $9.67 \times 10^{-6}\left( \pm 8.12 \times 10^{-6}\right)$ & $2.53 \times 10^{-6}\left( \pm 2.72 \times 10^{-6}\right)$ \\
\hline 82 & $1.93 \times 10^{-2}\left( \pm 4.11 \times 10^{-2}\right)$ & & & $9.08 \times 10^{-3}\left( \pm 4.31 \times 10^{-2}\right)$ \\
\hline 82 & $1.85 \times 10^{-5}\left( \pm 8.44 \times 10^{-6}\right)$ & $2.12 \times 10^{-6}\left( \pm 1.1 \times 10^{-6}\right)$ & $1.52 \times 10^{-5}\left( \pm 1.95 \times 10^{-5}\right)$ & $2.50 \times 10^{-5}\left( \pm 3.62 \times 10^{-5}\right)$ \\
\hline 87 & $2.32 \times 10^{-3}\left( \pm 1.36 \times 10^{-3}\right)$ & & & $2.46 \times 10^{-3}\left( \pm 3.78 \times 10^{-3}\right)$ \\
\hline 87 & $7.68 \times 10^{-5}\left( \pm 3.96 \times 10^{-5}\right)$ & $1.11 \times 10^{-5}\left( \pm 8.06 \times 10^{-6}\right)$ & $4.6 \times 10^{-5}\left( \pm 2.66 \times 10^{-5}\right)$ & $5.61 \times 10^{-5}\left( \pm 5.26 \times 10^{-5}\right)$ \\
\hline 92 & $3.77 \times 10^{-3}\left( \pm 3.03 \times 10^{-3}\right)$ & & & $3.23 \times 10^{-2}\left( \pm 1.67 \times 10^{-2}\right)$ \\
\hline 92 & $7.30 \times 10^{-5}\left( \pm 4.53 \times 10^{-5}\right)$ & $9.04 \times 10^{-6}\left( \pm 7.13 \times 10^{-6}\right)$ & $7.72 \times 10^{-5}\left( \pm 9.49 \times 10^{-5}\right)$ & $2.53 \times 10^{-4}\left( \pm 1.80 \times 10^{-4}\right)$ \\
\hline 108 & $6.75 \times 10^{-4}\left( \pm 2.03 \times 10^{-3}\right)$ & & & $7.61 \times 10^{-3}\left( \pm 1.15 \times 10^{-2}\right)$ \\
\hline 108 & $2.79 \times 10^{-5}\left( \pm 8.44 \times 10^{-6}\right)$ & $2.12 \times 10^{-6}\left( \pm 1.1 \times 10^{-6}\right)$ & $1.52 \times 10^{-5}\left( \pm 1.95 \times 10^{-5}\right)$ & $2.5 \times 10^{-5}\left( \pm 3.62 \times 10^{-5}\right)$ \\
\hline \multicolumn{5}{|c|}{ Mean values for stage 3} \\
\hline & $1.83 \times 10^{-3}\left( \pm 1.22 \times 10^{-3}\right)$ & & & $2.56 \times 10^{-2}\left( \pm 3.62 \times 10^{-2}\right)$ \\
\hline & $5.64 \times 10^{-5}\left( \pm 5.65 \times 10^{-5}\right)$ & $7.19 \times 10^{-6}\left( \pm 1.01 \times 10^{-5}\right)$ & $3.3 \times 10^{-5}\left( \pm 5.05 \times 10^{-5}\right)$ & $6.91 \times 10^{-5}\left( \pm 1.24 \times 10^{-4}\right)$ \\
\hline
\end{tabular}

Overall means

$1.39 \times 10^{-3}\left( \pm 1.11 \times 10^{-3}\right)$

$1.45 \times 10^{-4}\left( \pm 1.8 \times 10^{-4}\right)$

$1.39 \times 10^{-4}\left( \pm 6.42 \times 10^{-4}\right)$

$1.41 \times 10^{-3}\left( \pm 5.47 \times 10^{-3}\right)$

$1.59 \times 10^{-2}\left( \pm 2.77 \times 10^{-2}\right)$ $7.06 \times 10^{-4}\left( \pm 1.92 \times 10^{-3}\right)$ 

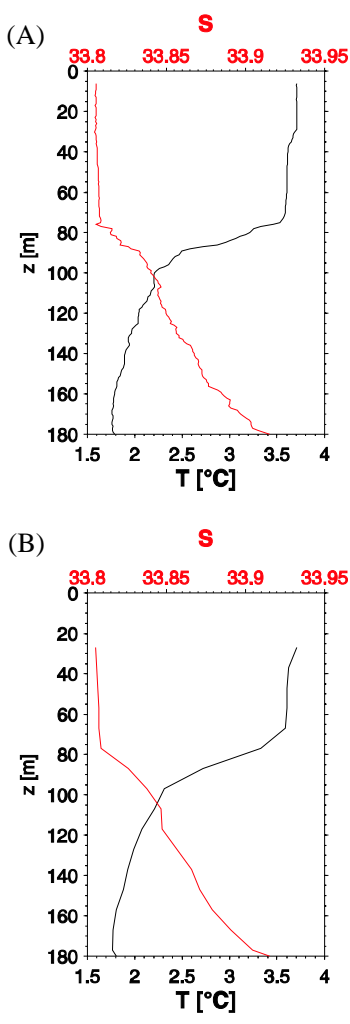

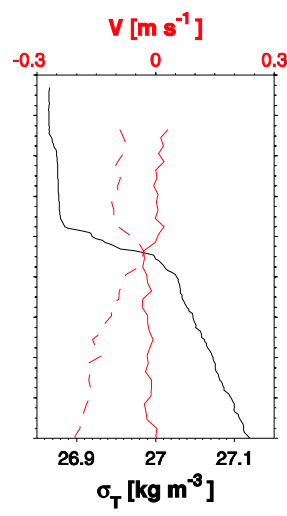

$\mathrm{V}\left[\mathrm{m} \mathrm{s}^{-1}\right]$

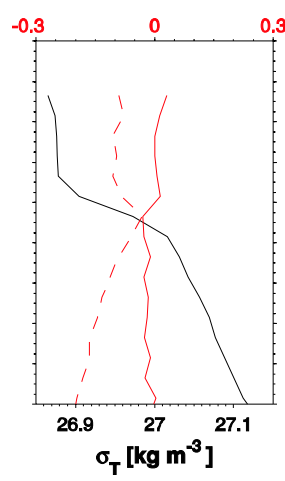

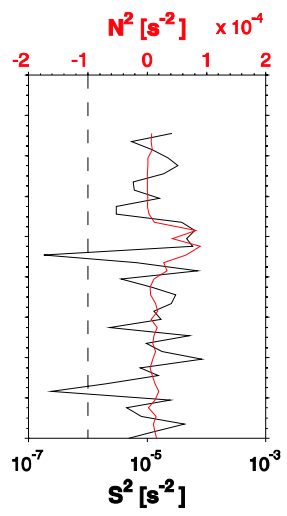

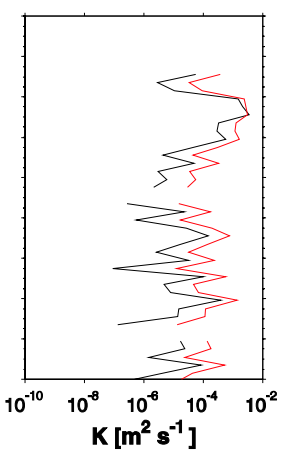

$\mathrm{N}^{2}\left[\mathrm{~s}^{-2}\right] \times 10^{-4}$
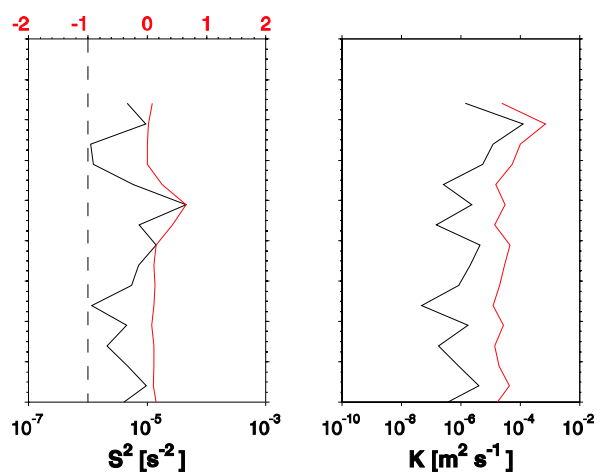

Fig. 7. CTD profiles at stations 87 (A) and (B), each panel shows temperature (black), salinity (red), potential density (black), ADCP $u$ - und $v$-components (red solid and red dashed), current shear squared (black) and noise level (dashed), buoyancy frequency squared (red), vertical eddy diffusivity after the parameterizations of Gregg (black) and Pacanowski and Philander (blue) calculated from 4 and $10 \mathrm{~m}$ data, respectively.

computed at a vertical resolution of $10 \mathrm{~m}$. The corresponding profiles are illustrated in Fig. 7B. While $N^{2}$ looks just smoothed, $S^{2}$ deviates from the $4-\mathrm{m}$ values by 1 to 2 orders of magnitude. However, comparing the full-depth averages for $K_{\mathrm{PP}}$ and $K_{\mathrm{G}}$ reveals that the results based on a $10-\mathrm{m}$ vertical resolution are less than 1 order of magnitude smaller than obtained at 4-m resolution. Therefore, we apply both $R i$-number-dependent parameterizations to the initially $4-\mathrm{m}$ averaged ADCP velocities.

\subsubsection{Comparison between methods}

The different estimates that have been obtained by the various methods, direct and indirect, relied exclusively on CTD and MSS casts that were performed at the same position and within a relatively short span of time (1-3h).

For the further discussion we divided the duration of the experiment into three periods representing three different stages of mixing. The initial phase of the experiment (6-11 November) was characterized by calm winds and mixed layer depths ranged between 26 and $45 \mathrm{~m}$. For this period we depicted as representatives stations 9, 11, 14, 18 and 38 (Figs. 8A-E). The second stage (11-16 November, stations 41, 43, 45, 46, 48 and 49) showed a mixed layer deepening down to $78 \mathrm{~m}$ associated with increasing wind speeds (Figs. 9A-F). The third and last stage (23-29 November, stations 78, 82, 87, 92 and 108) comprised mixed layer depths ranging between 
70 and $90 \mathrm{~m}$ (Figs. 10A-E), caused by the two preceding strong gale events during the 21 and 27 November.

As discussed before, the application of the four different methods is restricted to certain depth layers. We cannot rule out that haline effects, which were shown to corrupt all temperaturebased methods in the pycnocline below roughly $100 \mathrm{~m}$, impairs the Osborn-Cox method also in the mixed layer. The reason could be that OsbornCox works on micro-scale temperature gradients, which in reality might be compensated by microscale salinity gradients with respect to density. For our statistical analysis, temperature-based eddy diffusivities are therefore only taken into account and illustrated within those upper depth ranges where temperature dominates the density structure.

While we estimate the bulk eddy diffusivity from the parameterization of Pacanowski and Philander for the whole profile, Gregg's parameterization of internal wave-induced mixing is restricted to the stably stratified part of the water column. The corresponding profiles are illustrated in Figs. 8-10. Vertical averages are calculated for the mixed layer $[z<$ MLD] and for the upper thermocline $[\mathrm{MLD}<z<\mathrm{MLD}+20 \mathrm{~m}]$. These are illustrated in Fig. 11.

At stations 9, 11, 14, 18 and 38 (Figs. 8A-E), which were all performed during the period of calm winds and rather shallow mixed layers at the beginning of the experiment, $K_{\mathrm{PP}}$, and $K_{\mathrm{T}}^{\mathrm{CTD} \sigma}$ (derived from CTD density) agree in their shape over the full depth range. Above $100 \mathrm{~m} K_{\mathrm{PP}}$ also agrees with $K_{\mathrm{T}}^{\mathrm{MSS}}$ and $K_{\mathrm{T}}^{\mathrm{CTDT}}$, and, although less closely, with $K_{\mathrm{C}}$. The vertical averages for $K_{\mathrm{PP}}, K_{\mathrm{T}}^{\mathrm{CTDT}}, K_{\mathrm{T}}^{\mathrm{CTD} \sigma}$ and $K_{\mathrm{T}}^{\mathrm{MSS}}$ within the mixed layer range between $5.64 \times 10^{-4}$ and $3.49 \times 10^{-3}$, $4.75 \times 10^{-4}$ and $1.09 \times 10^{-2}, 6.94 \times 10^{-4}$ and $6.63 \times 10^{-3}, 4.77 \times 10^{-4}$ and $8.21 \times 10^{-3} \mathrm{~m}^{2} \mathrm{~s}^{-1}$ (Table 2).

While the wind speeds were low to moderate during the first stage, they increased during stage 2. Due to stronger winds the mixed layer deepened between station 41 and 43 (Figs. 9A-C). The vertical averages for $K_{\mathrm{PP}}, K_{\mathrm{T}}^{\mathrm{CTDT}}, K_{\mathrm{T}}^{\mathrm{CTD} \sigma}$ and $K_{\mathrm{T}}^{\mathrm{MSS}}$ within the mixed layer range between $4.8 \times 10^{-4}$ and $2.0 \times 10^{-3}, 2.48 \times 10^{-3}$ and $3.6 \times 10^{-2}, 1.63 \times$
$10^{-3}$ and $2.58 \times 10^{-2}, 8.86 \times 10^{-4}$ and $2.42 \times$ $10^{-2} \mathrm{~m}^{2} \mathrm{~s}^{-1}$ (Fig. 11A).

All stations, which were performed during the third stage, reveal a quasi-homogeneous mixed layer with depths ranging between 61 and $87 \mathrm{~m}$. All estimates of vertical diffusivity that are based on the density profile ( $K_{\mathrm{PP}}$ and $K_{\mathrm{T}}^{\mathrm{CTD} \sigma}$ ) show a similar vertical distribution, with distinctly (up to four orders of magnitude) higher values in the mixed layer than below. Quantitatively, however, these estimates differ from each other.

The vertical averages for $K_{\mathrm{PP}}, K_{\mathrm{T}}^{\mathrm{CTDT}}, K_{\mathrm{T}}^{\mathrm{CTD} \sigma}$ and $K_{\mathrm{T}}^{\mathrm{MSS}}$ within the mixed layer range between $6.75 \times 10^{-4}$ and $2.09 \times 10^{-1}, 2.26 \times 10^{-3}$ and $2.34 \times 10^{-1}, 9.63 \times 10^{-4}$ and $2.28 \times 10^{-2}, 2.46 \times$ $10^{-3}$ and $8.01 \times 10^{-2} \mathrm{~m}^{2} \mathrm{~s}^{-1}$ (Fig. 11A) and show a positive trend with time.

Eddy diffusivities below the mixed layer appear rather invariant against changes in atmospheric forcing (Figs. 8-11). The overall means for the upper thermocline are $K_{\mathrm{G}}=1.39 \times 10^{-4} \pm 6.42 \times$ $10^{-4} \mathrm{~m}^{2} \mathrm{~s}^{-1}, K_{\mathrm{PP}}=1.45 \times 10^{-4} \pm 1.8 \times 10^{-4} \mathrm{~m}^{2} \mathrm{~s}^{-1}$ and $K_{\mathrm{T}}^{\mathrm{MSS}}=7.06 \times 10^{-4} \pm 1.92 \times 10^{-3} \mathrm{~m}^{2} \mathrm{~s}^{-1}$. For comparison, ignoring the three different stages of mixing, the overall mean eddy diffusivities for the mixed layer are $K_{\mathrm{PP}}=1.39 \times 10^{-3} \pm 1.11 \times$ $10^{-3} \mathrm{~m}^{2} \mathrm{~s}^{-1} \quad$ and $\quad K_{\mathrm{T}}^{\mathrm{MSS}}=1.59 \times 10^{-2} \pm 2.77 \times$ $10^{-2} \mathrm{~m}^{2} \mathrm{~s}^{-1}$.

Independently, estimates of vertical diffusivity also were obtained from analysis of the vertical spreading of the inert tracer sulphur hexafluoride (SF6) and of dissolved iron, which were both released during EisenEx. From $\mathrm{SF}_{6}$, Laura Goldson (2003, personal communication) estimated a diffusivity of $3.5 \times 10^{-5} \pm 2.1 \times 10^{-5} \mathrm{~m}^{2} \mathrm{~s}^{-1}$ at the top of the pycnocline, to which our pycnocline mean value of $K_{\mathrm{G}}$ comes closest. From dissolved iron, assuming Fickian diffusion and using the second moment method (Law et al., 1998; Watson and Ledwell, 1990), Croot et al. (2003) calculated the vertical diffusivity at the bottom of the mixed for a 2-day period between the stations 46 and 49; they obtained a value $K_{z}=6.7 \times 10^{-4} \pm$ $0.7 \times 10^{-4} \mathrm{~m}^{2} \mathrm{~s}^{-1}$. For comparison, our mean mixed-layer values calculated for stations 46-49 are $K_{\mathrm{PP}}=9.3 \times 10^{-4} \pm 8.5 \times 10^{-4} \mathrm{~m}^{2} \mathrm{~s}^{-1}$ and $K_{\mathrm{T}}^{\mathrm{CTD} \sigma}=2.1 \times 10^{-2} \pm 6.5 \times 10^{-2} \mathrm{~m}^{2} \mathrm{~s}^{-1}$. Of these, the value of $K_{\mathrm{PP}}$ is, given by the range of 
(A)

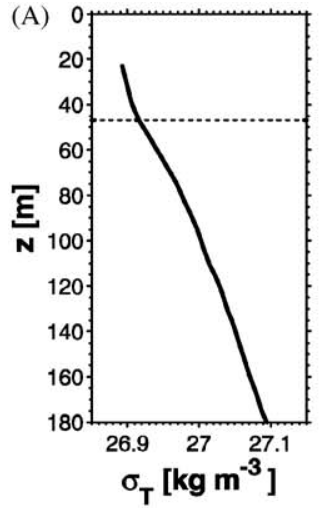

(C)

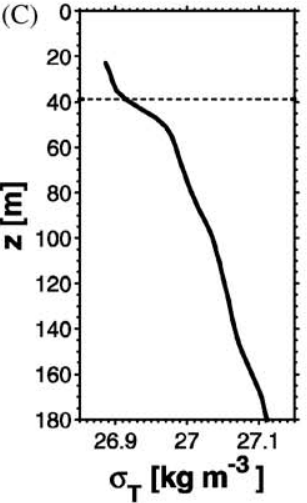

(E)

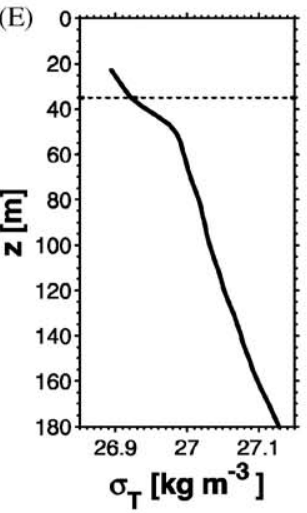

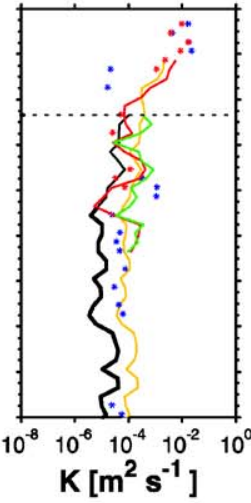

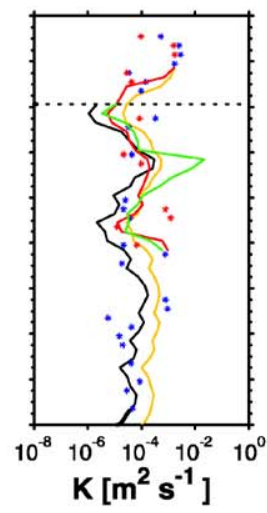

(D)
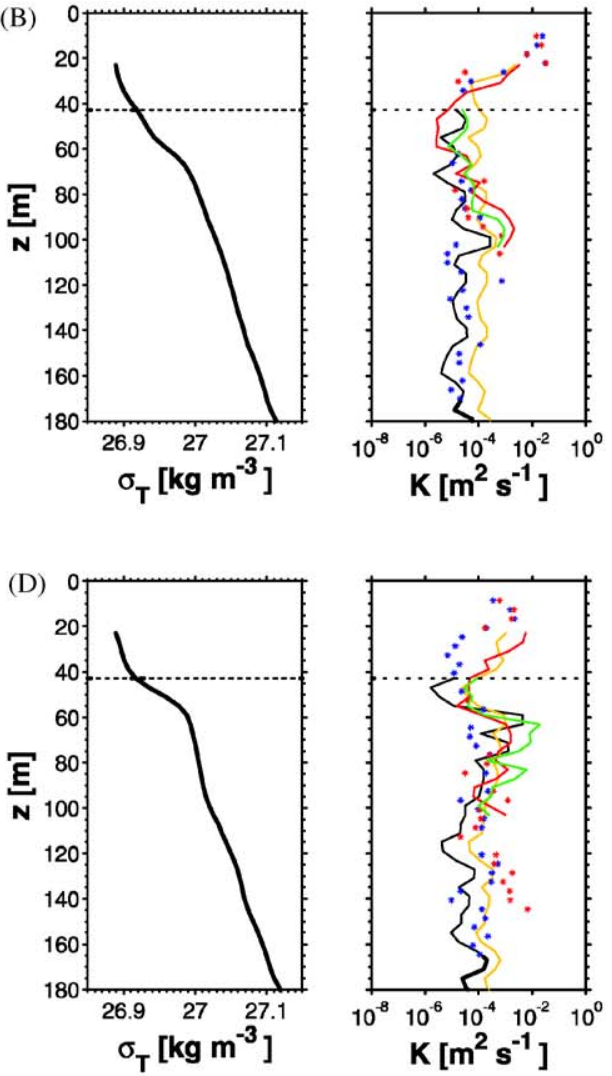

Fig. 8. (A)-(E) Figure pairs consisting of density profiles and calculated mixed layer depths (dotted line) for stations $9,11,14,18$ and 38 and their estimated vertical eddy diffusivities: $K_{\mathrm{G}}$ (black line), $K_{\mathrm{PP}}$ (yellow line), $K_{\mathrm{C}}$ (green line), $K_{\mathrm{T}}^{\mathrm{MSS}}$ calculated from MSS temperature (red line), $K_{\mathrm{T}}^{\mathrm{CTDT}}$ calculated from CTD temperature (red dots) and $K_{\mathrm{T}}^{\mathrm{CTD} \sigma}$ calculated from CTD density (blue dots).

uncertainty as indicated by the standard deviations, undistinguishable from the diffusivity coefficient determined from the dissolved iron diffusion.

\subsubsection{Previous measurements}

Estimates of vertical eddy diffusivities obtained from previous studies within the ACC were 

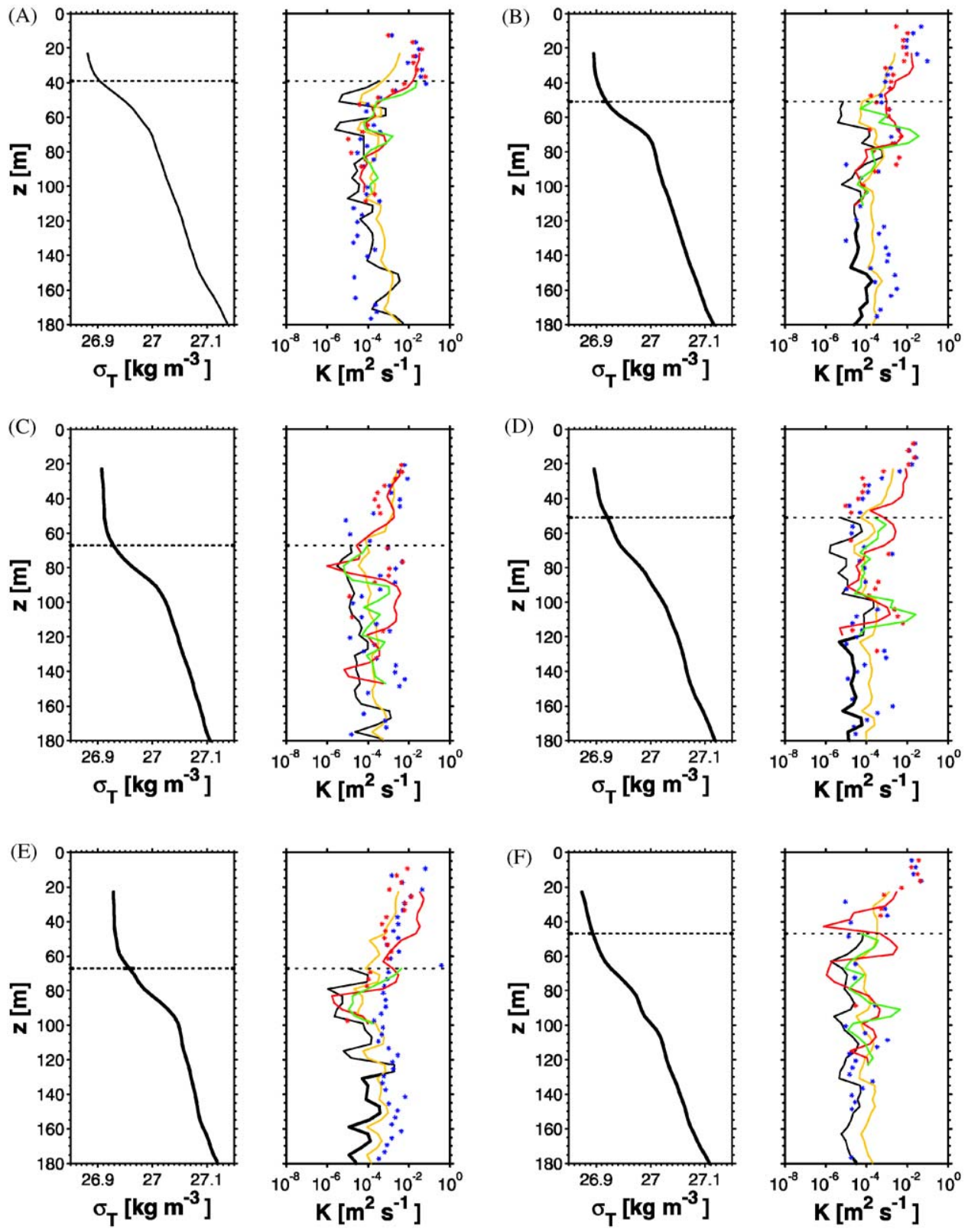

Fig. 9. (A)-(F) Figure pairs consisting of density profiles and calculated mixed layer depths (dotted line) for stations 41 , 43, 45, 46, 48 and 49 and their estimated vertical eddy diffusivities: $K_{\mathrm{G}}$ (black line), $K_{\mathrm{PP}}$ (yellow line), $K_{\mathrm{C}}$ (green line), $K_{\mathrm{T}}^{\mathrm{MSS}}$ calculated from MSS temperature (red line), $K_{\mathrm{T}}^{\mathrm{CTDT}}$ calculated from CTD temperature (red dots) and $K_{\mathrm{T}}^{\mathrm{CTD} \sigma}$ calculated from CTD density (blue dots).

derived from different parameterizations. Naveira Garabato et al. (2002) estimated the horizontal and vertical advection and the vertical diffusion of nitrate and silicate at the Antarctic Polar
Front (APF) in the Atlantic sector. The authors used the parameterizations after Pacanowski and Philander (1981) and Peters et al. (1988) for estimating the vertical eddy diffusivity $K_{z}$. Both 
(A)

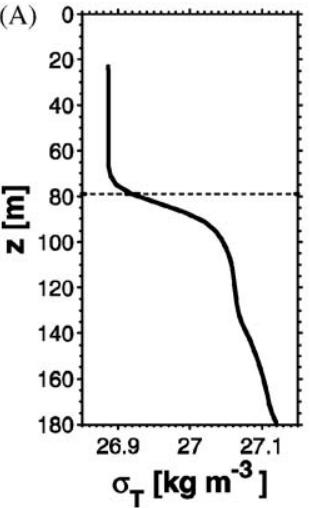

(C)

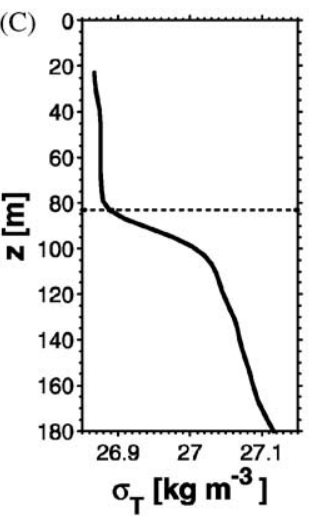

(E)

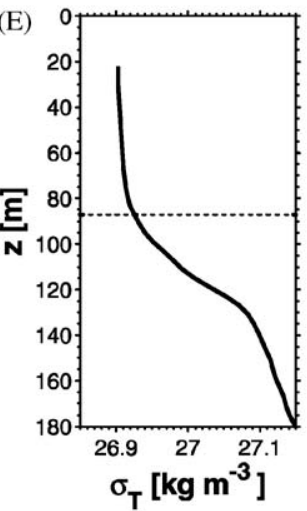

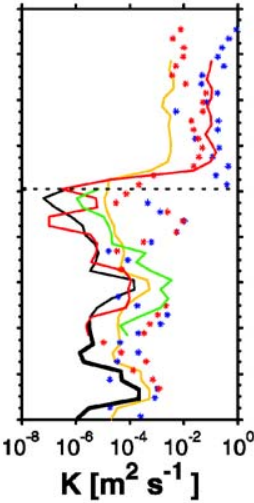

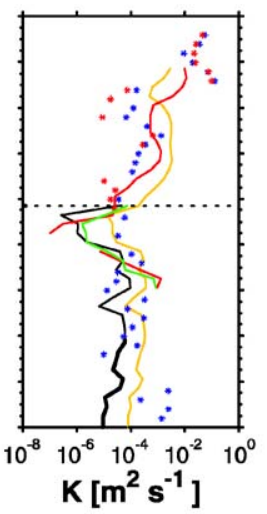

(D)

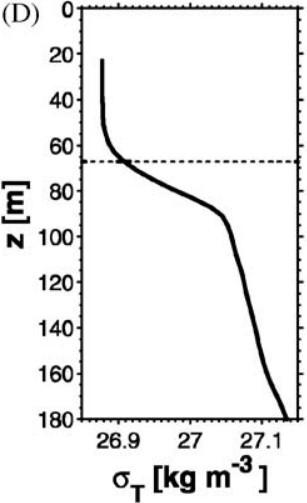

(B)

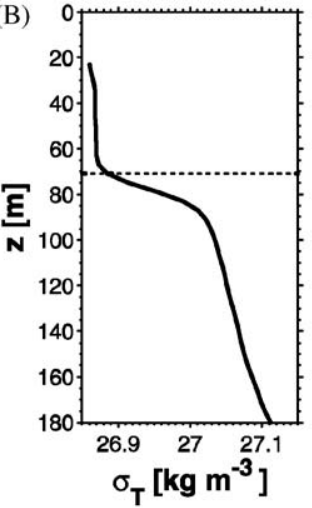

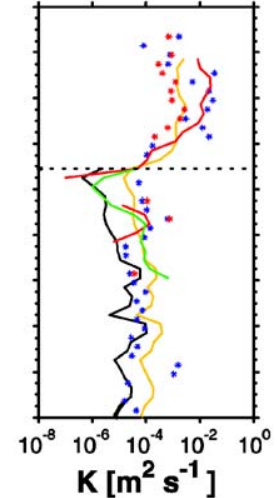

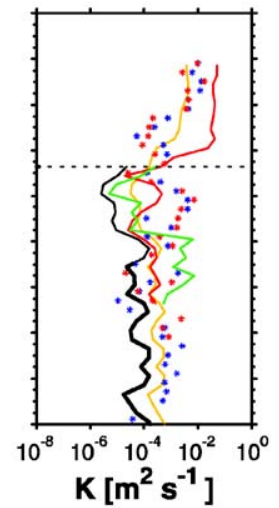

Fig. 10. (A)-(E) Figure pairs consisting of density profiles and calculated mixed layer depths (dotted line) for stations $78,82,87,92$ and 108 and their estimated vertical eddy diffusivities: $K_{\mathrm{G}}$ (black line), $K_{\mathrm{PP}}$ (yellow line), $K_{\mathrm{C}}$ (green line), $K_{\mathrm{T}}^{\mathrm{MSS}}$ calculated from MSS temperature (red line), $K_{\mathrm{T}}^{\mathrm{CTDT}}$ calculated from CTD temperature (red dots) and $K_{\mathrm{T}}^{\mathrm{CTD} \sigma}$ calculated from CTD density (blue dots).

parameterizations showed a close agreement at all depths except in the vicinity of the mixed-layer base, where high values of the gradient Froude number occurred. However, these values were never been checked against direct observations. Recently Law et al. (2003) published their estimates of vertical eddy diffusion performed during the Southern Ocean Iron Enrichment Experiment 

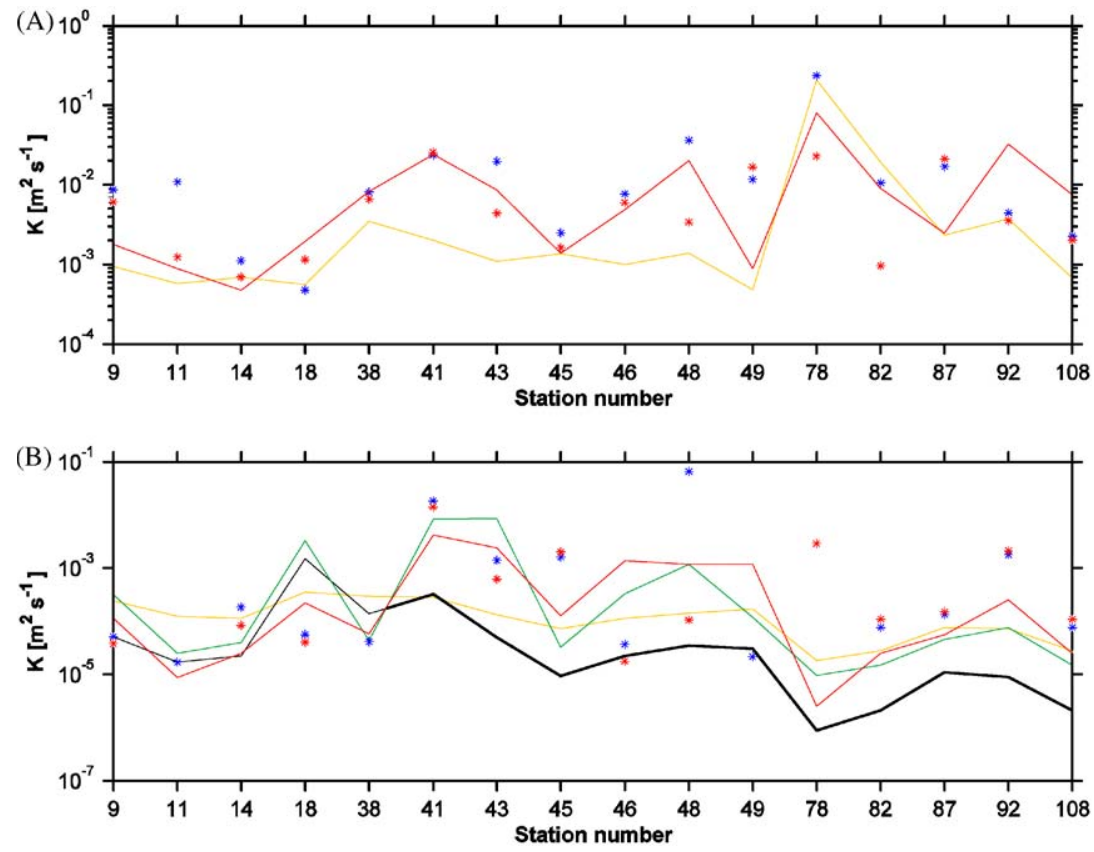

Fig. 11. Vertically averaged eddy diffusivities: (A) within mixed layer and (B) within upper thermocline illustrated for all stations: $K_{\mathrm{G}}$ (black line), $K_{\mathrm{PP}}$ (yellow line), $K_{\mathrm{C}}$ (green line), $K_{\mathrm{T}}^{\mathrm{MSS}}$ calculated from MSS temperature (red line), $K_{\mathrm{T}}^{\mathrm{CTDT}}$ calculated from CTD temperature (red dots) and $K_{\mathrm{T}}^{\mathrm{CTDT} \sigma}$ calculated from CTD density (blue dots).

(SOIREE) at $61^{\circ} \mathrm{S} 140^{\circ} \mathrm{E}$. From the dispersion of the tracer sulfur hexafluoride (SF6) they got an estimate of vertical exchange at the base of the mixed layer indicating that $K_{z}$ was less than $0.3 \times 10^{-4} \mathrm{~m}^{2} \mathrm{~s}^{-1}$. That this value is lower than our estimates by about 1 order of magnitude can be attributed to the fact that, in contrast to EisenEx, the wind speeds during the SOIREE experiment were comparably low. The authors reported that the wind speeds were low during the $\mathrm{SF}_{6} /$ iron release, but increased immediately afterwards and remained above $12 \mathrm{~m} \mathrm{~s}^{-1}$ until day 4 . The wind subsequently decreased to $\sim 5 \mathrm{~m} \mathrm{~s}^{-1}$, before increasing again to $12 \mathrm{~m} \mathrm{~s}^{-1}$ on day 9 and then subsiding to $\sim 5 \mathrm{~m} \mathrm{~s}^{-1}$ for the remainder of the SOIREE experiment (Law et al., 2003). While the method of Law et al. provides a temporally averaged estimate of the vertical eddy diffusion, it does not allow for resolving the temporal and spatial scales and for relating mixing to the driving mechanisms.

\section{Conclusions}

In this paper, we studied the vertical mixing regime of the upper $180 \mathrm{~m}$ of the water column, which encompassed the mixed layer and the seasonal pycnocline. The study was based on a Lagrangian experiment performed for a period of 23 days in an eddy shed by the APF. The Lagrangian experiment provides a clear focus on the temporal variations, related to changes of the atmospheric forcing during that time.

1. Due to the highly variable wind stress pattern, the response time of the mixed layer to the wind forcing is longer than predicted by the model of Pollard et al. (1973). If integrated for just one inertial period as in Pollard et al. the resultant correlation coefficient $r$ amounts to 0.4 , which is not statistically significant. However, if the integration time is increased to three inertial periods, $r$ converges to 0.83 indicating a 
significant correlation of wind-energy input and mixed-layer depth.

2. Estimates of vertical eddy diffusivity have been obtained from direct as well as from indirect methods. The comparison between the different methods for the estimation of the vertical eddy diffusivities in the mixed layer suggests a reasonable, within 1 order of magnitude, agreement between $K_{\mathrm{PP}}, K_{\mathrm{T}}^{\mathrm{CTD} \sigma}, K_{\mathrm{T}}^{\mathrm{CTDT}}$ and $K_{\mathrm{T}}^{\mathrm{MSS}}$. The Thorpe scale-based eddy diffusivities $K_{\mathrm{T}}^{\mathrm{CTDT}}$ and $K_{\mathrm{T}}^{\mathrm{MSS}}$, which just rely on the temperature profiles, are only applicable to the upper $90-120 \mathrm{~m}$ but not deeper, where haline gradients gain importance in affecting the vertical density distribution. The applicability of the Osborn-Cox method within a quasihomogeneous mixed layer is questionable, because the very small vertical temperature gradients lead to higher eddy diffusivities than estimated by all the other methods. In the pycnocline, $K_{\mathrm{G}}$ seems to yield values that are smaller by about 1 order of magnitude than those suggested by either $K_{\mathrm{PP}}$ or $K_{\mathrm{T}}^{\mathrm{CTD} \sigma}$.

3. Values of $K_{z}$ in the order of $10^{-4} \mathrm{~m}^{2} \mathrm{~s}^{-1}$ appear as a rather robust estimate of vertical diffusivity within the seasonal pycnocline. Values in the mixed layer above can be much higher, up to $10^{-1} \mathrm{~m}^{2} \mathrm{~s}^{-1}$, during vigorous atmospheric forcing. Although the dependence on wind speed is not surprising, it was not revealed by previous estimates of vertical diffusivity from the Southern Ocean, which relied on tracer diffusion experiments and hence represented an integrated measure over all turbulent events during the observation period.

\section{Acknowledgements}

This work was part of the iron fertilization experiment EisenEx (Polarstern cruise ANT XVIII/2), which was successfully conducted under the leadership of the Chief Scientist Victor Smetacek. Santiago Gonzales, Harry Leach, Johannes Post, Vagner da Silva Duarte, and Florian Trumm contributed substantially to the collection of the comprehensive hydrographic and microstructure data sets; Harry Leach also provided the optimal interpolation routines for calculating the streamfunction. Helmut Baumert helped with skillful processing of the MSS data. We gratefully acknowledge the support provided by the officers and crew of the R.V. Polarstern.

\section{References}

Baumert, H., Peters, H., 2000. Second-moment closures and length scales for weakly stratified turbulent shear flows. Journal of Geophysical Research 105, 6453-6468.

Croot, P.L., Laan, P., Nishioka, J., Strass, V.H., Cisewski, B., Boye, M., Timmermans, K.R., Bellerby, R.G., Goldson, L., Nightingale, P., de Baar, H.J.W., 2005. Spatial and temporal distribution of $\mathrm{Fe}(\mathrm{II})$ and $\mathrm{H}_{2} \mathrm{O}_{2}$ during EisenEx, an open ocean mesoscale iron enrichment, Marine Chemistry 95 (1-2), 65-68 [doi:10.1016/j.marchem.2004.06.041].

D'Asaro, E.A., Morison, J.H., 1992. Internal waves and mixing in the Arctic Ocean. Deep-Sea Research 39 (Suppl. 2), 459-484.

Dillon, T.M., 1982. Vertical overturns: a comparison of Thorpe and Ozmidov length scales. Journal of Geophysical Research 85, 9601-9613.

Dillon, T.M., Park, M.M., 1987. The available potential energy of overturns as indicator of mixing in the seasonal thermocline. Journal of Geophysical Research 92, 5345-5353.

Ferron, B., Mercier, H., Speer, K., Gargett, A., Polzin, K., 1998. Mixing in the Romanche fracture zone. Journal of Physical Oceanography 28, 1929-1945.

Finnigan, T.D., Luther, D.S., Lukas, R., 2002. Observations of enhanced diapycnal mixing near the Hawaiian Ridge. Journal of Physical Oceanography 32, 2988-3002.

Galbraith, P.S., Kelley, D.E., 1996. Identifying overturns in CTD profiles. Journal of Atmospheric Oceanic Technology 13, 688-702.

Garrett, C.J.R., Munk, W.H., 1979. Internal waves in the oceans. Annual Review of Fluid Mechanics 11, 339-369.

Gregg, M.C., 1989. Scaling turbulent dissipation in the thermocline. Journal of Geophysical Research 94, 9686-9698.

Häkkinen, S.D., Cavalieri, J., 1989. A study of oceanic surface heat fluxes in the Greenland, Norwegian and Barents Seas. Journal of Geophysical Research 94, 6145-6157.

Itsweire, E.C., 1984. Measurements of vertical overturns in a stably stratified turbulent flow. Journal of Fluid Mechanics 27, 764-766.

Large, W.G., Pond, S., 1981. Open ocean flux measurements in moderate to strong winds. Journal of Physical Oceanography $11,324-336$.

Law, C.S., Liddicoat, M.I., Watson, A.J., Stanton, T., 1998. Sulphur hexafluoride as a tracer of biogeochemical and physical processes in an open-ocean iron fertilisation experiment. Deep-Sea Research Part II 45, 977-994. 
Law, C.S., Abraham, E.R., Watson, A.J., Liddicoat, M.E., 2003. Vertical Eddy diffusion and nutrient supply to the surface mixed layer of the Antarctic Circumpolar Current. Journal of Geophysical Research 108 (8), 3272.

Lorke, A., 1988. Turbulenz und Mischung in einem polymiktischen See-Untersuchungen auf der Basis von Mikrostrukturmessungen. Ph.D. Thesis, Technical University of Darmstadt, Germany.

Lorke, A., Wüest, A., 2002. Probability density of displacement and overturning length scales under diverse stratification. Journal of Geophysical Research 107, doi:10.1029/ 2001JC001154.

Lueck, R.G., Wolk, F., Yamazaki, H., 2002. Oceanic velocity microstructure measurements in the 20th century. Journal of Oceanography 58, 153-174.

Millard, R.C., Owens, W.B., Fofonoff, N.P., 1990. On the calculation of the Brunt-Väisälä frequency. Deep-Sea Research 37, 167-181.

Moum, J.N., 1996. Energy-containing scales of turbulence in the ocean thermocline. Journal of Geophysical Research 101, 14095-14109.

Naveira Garabato, A.C., Strass, V.H., Kattner, G., 2002. Fluxes of nutrients in a three-dimensional meander structure of the Antarctic Polar Front. Deep-Sea Research Part II 49, 3771-3792.

Niiler, P.P., Kraus, E.B., 1977. One-dimensional models of the upper ocean. In: Kraus, E.B. (Ed.), Modelling and Prediction of the Upper Layers of the Ocean. Pergamon, New York, pp. 143-172.

Osborn, T.R., 1980. Estimates of the local rate of vertical diffusion from dissipation measurements. Journal of Physical Oceanography 10, 83-89.

Osborn, T.R., Cox, C.S., 1972. Oceanic fine structure. Geophysical Fluid Dynamics 3, 321-345.

Pacanowski, R.C., Philander, S.G.H., 1981. Parameterization of vertical mixing in numerical models of the tropical oceans. Journal of Physical Oceanography 11, 1443-1451.
Peters, H., Gregg, M.C., Toole, J.M., 1988. On the parameterization of equatorial turbulence. Journal of Geophysical Research 93, 121-1199.

Pollard, R.T., Rhines, P.B., Thompson, R.O.R.Y., 1973. The deepening of the wind mixed layer. Geophysical Fluid Dynamics 4, 381-404.

Prandke, H., Holtsch, K., Stips, A., 2000. MITEC Report Technical Note No. 1.96.87. European Commission, Joint Research Centre, Space Applications Institute, Ispra/Italy.

RD Instruments, RD-VM Model Acoustic Doppler Current Profiler with IBM compatible DAS-Operation and Maintenance Manual, 1987.

Rintoul, S., Hughes, C., Olbers, D., 2001. The Antarctic circumpolar current system. In: Siedler, G., Church, J., Gould, J. (Eds.), Ocean Circulation and Climate. Academic Press, New York, pp. 271-302.

Smetacek, V., 2001. EisenEx. International team conducts iron experiment in the Southern Ocean. U.S. JGOFS Newsletter 11 (1), 11-14.

Stansfield, K., Garret, C., Dewey, R.K., 2001. The probability distribution of Thorpe displacement with overturns in the Juan de Fuca Strait. Journal of Physical Oceanography 31, 3421-3434.

Strass, V.H., Naveira Garabato, A.C., Pollard, R.T., Fischer, H.I., Hense, I., Allen, J.T., Read, J.F., Leach, H., Smetacek, V., 2002. Mesoscale frontal dynamics: shaping the environment of primary production in Antarctic circumpolar current. Deep-Sea Research II 49, 3735-3769.

Thorpe, S.A., Turbulence and mixing in a Scottish Loch. Philosophical Transactions of the Royal Society of London, Series A 286, 125-18.

Watson, A.J., Ledwell, J.R., 1990. Purposefully released tracers. In: Charnock, H., Lovelock, J.E., Liss, P.S., Whitfield, M. (Eds.), Tracers in the Ocean. Princeton University Press, Princeton, NJ, pp. 189-200.

Wunsch, C., Ferrari, R., 2004. Vertical mixing, energy, and the general circulation of the oceans. Annual Review of Fluid Mechanics 36, 281-314. 